\title{
Coordenação Intragovernamental para a Implementação da Política Externa Brasileira: 0 Caso do Fórum IBAS*
}

\author{
Carlos Aurélio Pimenta de Faria ${ }^{1}$ \\ Joana Laura Marinho Nogueira ${ }^{2}$ \\ Dawisson Belém Lopes ${ }^{3}$
}

${ }^{1}$ Professor dos Programas de Pós-Graduação em Ciências Sociais e em Relações Internacionais da Pontifícia Universidade Católica de Minas Gerais (PUC-Minas), pesquisador do Conselho Nacional de Desenvolvimento Científico e Tecnológico (CNPq) e da Fundação de Amparo à Pesquisa do Estado de Minas Gerais (Fapemig). E-mail: carlosf@pucminas.br.

${ }^{2}$ Mestre em Relações Internacionais pela Pontifícia Universidade Católica de Minas Gerais (PUC-Minas). E-mail: joanalaura@gmail.com.

${ }^{3}$ Professor do Departamento de Ciência Política da Universidade Federal de Minas Gerais (UFMG). E-mail: dawisson@fafich.ufmg.br.

$1 \begin{aligned} & \text { o presente contexto de progressivo adensamento das relações in- } \\ & \text { ternacionais do Brasil, que tem acarretado a sua crescente politi- }\end{aligned}$ zação e a emergência de novos stakeholders, diversos estudos detectam uma perda, ainda que relativa, da capacidade do Itamaraty de coordenar a política externa brasileira. Contudo, se nos últimos anos a comunidade acadêmica brasileira tem se dedicado, de maneira mais sistemática, à análise do modo como o Ministério das Relações Exteriores (MRE) interage com o Poder Legislativo (Alexandre, 2006, 2007; Diniz e Ribeiro, 2008, 2010; Ferreira, 2010; Lima, 2002; Lima e Santos, 2001; Maia e César, 2004; Neves, 2003, 2006; Oliveira, A., 2003) e com os grupos de interesse domésticos (Carvalho, 2003; Cason e Power, 2006; Oliveira e Pfeifer, 2006; Oliveira e Onuki, 2007; Oliveira, M., 2003; Santana, 2001), na agenda de trabalho dos pesquisadores da área ainda há, claramente, uma lacuna importante, relativa à maneira como o Itamaraty procura, na produção da política exterior, articular os demais atores governamentais, que não raro têm interesses e métodos divergentes daqueles da diplomacia do país.

\footnotetext{
* Uma versão anterior deste artigo foi apresentada no II Encontro da Associação Brasileira de Relações Internacionais, na cidade do Rio de Janeiro, em julho de 2009. A pesquisa que deu origem a este trabalho contou com o financiamento do Conselho Nacional de Desenvolvimento Científico e Tecnológico $(\mathrm{CNPq})$ e da Fundação de Amparo à Pesquisa do Estado de Minas Gerais (Fapemig), a quem os autores gostariam de agradecer. Cabe ainda uma palavra de reconhecimento aos pareceristas anônimos de DADOS, por suas valiosas sugestões ao texto original.
}

DADOS - Revista de Ciências Sociais, Rio de Janeiro, vol. 55, n-1, 2012, pp. 173 a 220. 
Na verdade, existe hoje uma bibliografia já significativa que, reconhecendo a centralidade do Itamaraty na produção da política exterior brasileira (ou quase monopólio, segundo alguns críticos), se dedica à apreciação empírica do papel efetivamente desempenhado pelo Itamaraty e à relevância de suas estruturas e dinâmicas organizacionais, qual seja: Barros (1986) e Cheibub $(1985 ; 1989)$ e, mais recentemente, Vigevani e Mariano (1997); Figueira (2010); Moura (2006; 2007); Puntigliano (2008); Silva, Spécie e Vitale (2010) e Belém Lopes (2011).

Note-se, contudo, que o interesse dos analistas da política externa brasileira tem, via de regra, se concentrado nos processos argumentativos, decisórios e de negociação com os parceiros internacionais. A exemplo do ocorrido anteriormente na academia estadunidense, na qual a implementação era considerada, nos anos 1970, como o "elo perdido" do processo de produção das políticas públicas, no Brasil parecem ser ainda esparsos os esforços de compreensão dos estilos, impactos, condicionantes e resultados da implementação. Como questão conexa, parece também subapreciado o papel das burocracias públicas como atores na produção das políticas, capazes e muitas vezes legitimadas não apenas para a execução das diretrizes emanadas dos atores propriamente políticos, mas também atuando, em larga medida, como formuladoras (Faria, 2011). O presente artigo parte do reconhecimento daquela lacuna, centrando-se na apreciação dos mecanismos e estruturas organizacionais adotados pelo Itamaraty com o intuito de promover a coordenação dos demais atores governamentais, no nível doméstico, para a implementação das diretrizes do Fórum IBAS (Índia, Brasil e África do Sul), criado em 2003.

A inovadora iniciativa conjunta envolvendo os três Estados intermediários - Índia, Brasil e África do Sul - afigura-se peça fundamental da estratégia de cooperação entre os países do hemisfério Sul, a qual constituiu pilar da gestão de política externa do presidente Luiz Inácio Lula da Silva e de seu chanceler, Celso Amorim, entre 2003 e 2010 (Lima, 2005; Cervo, 2010). Importa notar também que a relativa maturidade do arranjo institucional do Fórum IBAS (já devidamente implementado e em funcionamento nos dias correntes) permitirá aos autores do artigo investigar com mais profundidade e detalhamento as dificuldades operacionais de levar a cabo a política externa tal como fora concebida, bem como as consequências momentâneas da sua implementação. Trata-se, afinal, de um caso que, apesar de recente e ainda por desdobrar-se, já apresenta contornos bem definidos, despertando o inte- 
resse dos estudiosos em função de sua relevância presente e, presumivelmente, futura.

Tendo em vista nosso objetivo principal, o artigo está organizado da seguinte maneira: na primeira seção, são apresentados, mui brevemente, os fatores que parecem explicar o insulamento do Itamaraty. Nessa seção são também arroladas evidências recentes de um comportamento organizacional, por parte do Ministério das Relações Exteriores (MRE), no sentido da busca de superação desse insulamento. A segunda seção, igualmente breve, procura compreender o significado do Fórum IBAS nas estratégias de inserção internacional adotadas durante a gestão do presidente Luiz Inácio Lula da Silva. A terceira apresenta a estrutura organizacional do IBAS, destacando os distintos instrumentos de coordenação inter e intragovernamental adotados. Ênfase é dada a esses últimos, que têm o objetivo de garantir a coordenação da atuação de uma diversidade de agências do governo federal brasileiro, envolvidas na busca de concretização dos objetivos do Fórum. A quarta seção apresenta uma discussão sucinta acerca da necessidade e dos tipos de estruturas usualmente implantadas para a produção da coordenação das atividades das agências estatais no plano intragovernamental. Na quinta seção do trabalho, os mecanismos de coordenação adotados pelo governo brasileiro para a implementação doméstica das diretrizes do IBAS são classificados, sendo a sua dinâmica brevemente analisada. Nas considerações finais, é questionada a suposta perda de capacidade de coordenação intragovernamental do Itamaraty.

\section{O ITAMARATY: DO INSULAMENTO À BUSCA DE COORDENAÇÃO INTRAGOVERNAMENTAL, INTERGOVERNAMENTAL E INTERSETORIAL}

Como discutido por Faria (2008), parece haver hoje um quase consenso entre os analistas da política exterior do Brasil, bem como entre diversos de seus stakeholders da sociedade civil, acerca do caráter insulado do processo de produção de tal política no país. De maneira sumária, é possível afirmarmos que a tradicional centralização do processo de formação da política externa no Itamaraty pode ser compreendida pela confluência de distintos fatores, quais sejam: (a) o arcabouço constitucional do país, que concede grande autonomia ao Executivo nesta matéria, relegando o Legislativo a uma posição marginal, o que também ocorre na maior parte dos países; (b) o fato de o Congresso brasileiro ter delegado ao Executivo a responsabilidade pela formação da política externa; (c) o caráter "imperial" do presidencialismo brasileiro; (d) o 
fato de o modelo de desenvolvimento por substituição de importações ter gerado uma grande introversão e insulamento dos processos políticos e econômicos do país, redundando em grande isolamento internacional do Brasil, reduzido a partir do início da década de 1990; (e) o caráter normalmente não conflituoso e largamente adaptativo da atuação diplomática do país; e, por fim, mas não menos importante, (f) a significativa e precoce profissionalização da corporação diplomática do país, associada ao prestígio de que desfruta o Itamaraty nos âmbitos doméstico e internacional.

Tais fatores, somados, parecem explicar o baixo grau de politização da política externa do país, pelo menos até o final dos anos 80 , o que reforça e justifica o insulamento do Itamaraty, que parece ainda encarar a política externa principalmente como uma política de Estado.

Desde a década passada, contudo, a aceleração do processo de globalização, a mudança no paradigma de inserção internacional do país, o adensamento das relações internacionais do Brasil e a politização de sua política externa têm redundado em crescentes pressões, políticas, societárias e também intragovernamentais, para que a produção da política externa do país passe a ser menos centralizada no Itamaraty. Elemento central neste processo é, como discutido por Lima (2000), o aumento do impacto distributivo da política externa do país. Como demonstra a literatura sobre o papel do empresariado nacional e do Legislativo na produção de tal política, listada há pouco, há mobilizações de diversas ordens voltadas ao questionamento da postura do Ministério das Relações Exteriores, tida como excessivamente insulada.

Há, contudo, diversas evidências recentes que apontam, se não para a plena superação deste padrão insulado de formação da política, pelo menos para um comportamento organizacional, por parte do MRE, no sentido da adoção de um padrão mais cooperativo. Tais evidências, analisadas em maior detalhe por Faria (2009), serão rapidamente arroladas aqui. Elas apontam mudanças no comportamento do Itamaraty em diversas direções, quais sejam: (a) na busca por uma maior coordenação intragovernamental, isto é, de uma articulação mais estreita com os demais ministérios e agências do governo federal; (b) na intensificação da busca por uma cooperação intergovernamental mais ampla, isto é, de maior articulação entre o Itamaraty e os governos subnacionais, que têm demonstrado grande ativismo em suas ações internacionais; $\mathrm{e}$ (c) no plano intersetorial, ou seja, de articulação entre o governo fede- 
ral e as entidades do mercado (segundo setor) e a sociedade civil (em que proliferam as entidades do chamado terceiro setor).

No que diz respeito à busca, por parte do Itamaraty, de uma maior coordenação intragovernamental, pode-se mencionar, muito sumariamente, não apenas as próprias estruturas de articulação instituídas pelo MRE para a implementação das diretrizes e políticas do IBAS, como será discutido neste trabalho, mas também iniciativas como: os Cursos de Capacitação em Relações Internacionais ministrados para altos funcionários do governo federal, das autarquias e das agências reguladoras pela Fundação Alexandre de Gusmão (Funag), vinculada ao Itamaraty; a oferta de apoio, doméstico e no exterior, a uma ampla gama de atividades internacionais desenvolvidas pelos vários órgãos do governo federal, incluindo a cessão de diplomatas para atuarem junto às assessorias de relações internacionais, presentes hoje na maior parte dos organismos da administração federal, entre outras. Cabe reiterarmos que esta área de atuação do MRE ainda é virtualmente inexplorada pelos analistas acadêmicos da política externa do país, sendo exceção o trabalho de Figueira (2010).

No plano intergovernamental, as iniciativas do Itamaraty são concentradas no âmbito da Assessoria Especial de Assuntos Federativos e Parlamentares (AFEPA), cuja atuação ainda precisa ser mais bem investigada. Nesse plano, têm papel de destaque os oito Escritórios Regionais do Itamaraty, quais sejam: EREMINAS (Escritório de Representação em Minas Gerais); EREPAR (Escritório de Representação no Paraná); ERESC (Escritório de Representação em Santa Catarina); ERESUL (Escritório de Representação no Rio Grande do Sul); ERERIO (Escritório de Representação no Rio de Janeiro); ERESP (Escritório de Representação em São Paulo), todos com sede nas capitais dos respectivos estados, e o ERENOR (Escritório de Representação na Região Norte, antigo EREMA), com sede em Manaus, e o ERENE (Escritório de Representação no Nordeste), com sede em Recife. Parece haver indícios de que é crescente o ativismo desses escritórios, criados a partir de 1995. Cabe destacar que os EREs buscam cooperar, em uma vasta gama de assuntos internacionais, não apenas com os governos subnacionais, mas também com toda sorte de atores societários, indivíduos e organizações.

No que concerne às articulações intersetoriais, ou seja, às interações do governo federal com as entidades do mercado e a sociedade civil, as 
evidências talvez sejam contraditórias. No primeiro caso, Oliveira e Pfeifer (2006) afirmam ter havido não apenas uma mudança no padrão de relacionamento entre o empresariado e o Itamaraty durante o governo Lula, mas também uma certa retração, após um processo de maior institucionalização das interações durante o governo precedente, a despeito do fato de que, em "alguns aspectos, houve uma aproximação estreita e resultados auspiciosos" (ibidem:400). Seja como for, no caso das interações do primeiro com o segundo setor, no âmbito da política externa, a literatura existente é quase unânime ao enfatizar a vigência de interações ainda aquém das desejáveis.

Contudo, no que diz respeito às articulações do Itamaraty com a sociedade civil, parece pertinente sugerirmos uma sensível ampliação da diplomacia pública durante o governo Lula, não apenas no sentido da projeção de uma dada imagem do Brasil no exterior, mas também de divulgação da política externa do país no âmbito doméstico. É esta segunda vertente da diplomacia pública brasileira que mais se associa com a temática explorada no presente artigo. Nesse campo, cabe, inicialmente, mencionarmos a criação do canal oficial do MRE no YouTube (http:/ / www.youtube.com/mrebrasil), no qual é possível ter acesso a vídeos e áudios de programas, entrevistas e coletivas do Ministro de Estado, diplomatas e outras autoridades sobre temas de política externa. A página é relativamente nova (foi criada em 18 de fevereiro de 2009), mas já tem 470 vídeos, que foram exibidos 490.179 vezes (dado do dia 16/4/2012, às 17 horas).

Destaque-se, ainda, o crescente ativismo da Funag, criada em 1971. Em recente balanço feito pela Fundação em seu Newsletter de 18/6/2009, são listadas as inúmeras atividades realizadas em 2008 com o intuito de "popularizar a política internacional", de "aproximar a política internacional do cotidiano do cidadão". Os números do balanço feito pela Funag são expressivos: em 2008 a Fundação "publicou 116 títulos [dos 620 em catálogo, todos disponíveis na internet], realizou 20 eventos, ministrou cinco cursos e criou bibliotecas em todas as regiões do país" $^{1}$. A Fundação também criou programas para a distribuição gratuita de livros relacionados à diplomacia do país e à sua política externa, bem como passou a fomentar um diálogo mais sistemático com a comunidade de investigadores acadêmicos das relações internacionais do país. Cabe recordarmos, ainda, que, a exemplo do que acontecia antes, o ministro das Relações Exteriores do governo Lula procurou divulgar, com intensidade significativa, as estratégias e resultados da 
política externa, por intermédio de artigos publicados na mídia impressa. Uma eventual maior receptividade do MRE aos aportes e demandas externos, ou o caráter bidirecional destas interações, contudo, ainda é uma questão a merecer estudos específicos.

\section{O FÓRUM IBAS E A POLÍTICA EXTERNA BRASILEIRA}

O Fórum Trilateral de Diálogo Índia, Brasil e África do Sul (IBAS) foi criado em 2003, pela Declaração de Brasília. Seus objetivos principais são: promover o diálogo Sul-Sul, a cooperação e a convergência do posicionamento de seus membros em assuntos de importância internacional; desenvolver oportunidades de comércio e investimento entre as três regiões, trabalhar a redução internacional da pobreza e em favor do desenvolvimento social; promover a troca de informação trilateral, melhores práticas internacionais, o intercâmbio de tecnologias e habilidades, assim como complementar os respectivos esforços de sinergia coletiva, buscando a cooperação em diversas áreas, como agricultura, mudança do clima, cultura, defesa, educação, energia, saúde, sociedade de informação, ciência e tecnologia, desenvolvimento social, comércio e investimento, turismo e transporte ${ }^{2}$.

Se, em um primeiro momento, a política externa brasileira (PEB) esteve visceralmente ligada à defesa da independência e do recém-formatado território nacional, pode-se afirmar que o início do século XX inaugurou um outro modus para a inserção internacional do Brasil: o país assume, de forma flagrante, a tática de aproximação com o centro do poder mundial (com Londres e, mais destacadamente, com Washington), tática essa que seria retomada por praticamente todos os presidentes da República. O grau dessa aproximação e a forma pela qual ela se desenvolveu vão variar com o tempo. Todavia, o que se manteve mais ou menos constante, no curso de nossa história republicana, foi o emprego da PEB a serviço do desenvolvimento econômico nacional (Lima, 2000; Cervo e Bueno, 1992). Assim, independentemente do modo como se dava a inserção brasileira em um momento específico da história (equidistante, pragmática, autônoma, associada, responsável, altiva etc.), as preocupações quanto ao desenvolvimento nacional estiveram conectadas às relações com o Norte - a força motriz da economia mundial.

Em regra, as relações com o Sul observaram sua função "complementar ao Norte" (Cervo e Bueno, 1992:374). Situações muito específicas 
constituíram exceção a essa regra. No campo da segurança (regional, hemisférica ou global), por exemplo, a tendência não foi a de associação com o Norte, por motivos já bem conhecidos. Na América do Sul, as consternações acerca da segurança regional, da balança de poder e da manutenção do status quo, quando ocorreram, nunca desfavoreceram o Brasil. O país apenas manteve seu horizonte de política exterior no Sul quando questões de vizinhança (normalmente ligadas à segurança) estiveram no centro da agenda nacional, ou seja, quando se precisou agregar força de barganha em fóruns multilaterais pela "causa sulista" ou quando o Sul se transformou em único trampolim para voos mais altos (rumo ao Norte), como se nota nas décadas de 1970 e 80 (Belém Lopes e Vellozo Júnior, 2004).

De forma inovadora, portanto, a gestão da PEB de Lula parece ter encontrado, no Sul, o local; e na tática de aproximação, via eixo Sul-Sul, a oportunidade para implementar uma estratégia maior: pensar os ganhos e o relacionamento do Brasil em relação ao Sul não apenas como complementares às suas relações com o Norte. O governo Lula identificava nessas incursões - dentre as quais se destaca o Fórum IBAS - a oportunidade de "unir semelhantes" para suprir o atraso tecnológico e econômico nacional, por intermédio de alianças, e de pressionar por uma nova governança global, capaz de espelhar e promover uma maior simetria entre Norte e Sul.

Em um contexto de extrema concentração da renda mundial no hemisfério Norte, que benefício pode haver nas chamadas estratégias de desenvolvimento Sul-Sul? É necessário aplacar a alegação de pretensa irracionalidade econômica e política dessas estratégias. Conforme aponta o relatório anual do Banco Mundial, os países em desenvolvimento (PEDs), tomados em conjunto, contabilizam aproximadamente $25 \%$ do Produto Nacional Bruto (PNB) mundial (World Bank Indicators, 2002). Ainda há que se ter em conta que os índices (nos últimos vinte anos) e projeções de crescimento dos PEDs em muito superam aqueles dos países do Norte desenvolvido. Além disso, os PEDs concentram mais da metade do mercado consumidor global. Ante o gigantismo demográfico do Sul não desenvolvido, aumentos nos níveis de renda per capita das populações de economias periféricas significam um enorme potencial multiplicador de consumo (vertido em aumento de exportações ou de produção no mercado interno, para os empreendedores que nesses mercados puderem penetrar) (ibidem). Rubens Ricupero (2004) endossa o argumento: “tem razão o presidente Lula: 
uma nova geografia do comércio se delineia. Para japoneses e americanos, os mercados das economias emergentes se aproximam de $50 \%$ de suas exportações e importações".

Partindo de uma concepção ampliada do desenvolvimento, que privilegia os seus aspectos não econômicos, qual vem a ser a atratividade das parcerias desenvolvimentistas Sul-Sul, tais como o Fórum IBAS? Aqui, os motivos são mais intuitivos, porém não óbvios. Dividamo-los em três frentes: (i) os desafios comuns da globalização; (ii) a reforma do sistema internacional; e (iii) o diálogo sobre governança nacional. Questões como a liberalização de mercados financeiros, a competitividade (espúria) no comércio internacional, os fluxos migratórios e a destinação de investimentos internacionais demarcam o campo de reflexão da primeira categoria. No tocante à governança global, o eixo Sul-Sul permanece valioso para a cooperação política. A esse respeito, Ignacy Sachs (1997:73) vislumbra: "a competição provável entre os três blocos de países industrializados - América do Norte, Europa e Japãopossivelmente criará oportunidades de um novo tipo de neoneutralismo". O pleito pela reforma da Organização das Nações Unidas (ONU) e as ações concertadas na Organização Mundial do Comércio (OMC) dão corpo a esse conceito. Por fim, no relativo ao compartilhamento de "melhores práticas" de gestão interna dos PEDs, Ricupero, novamente, toma a palavra: "não podemos [países em desenvolvimento] nos comparar aos Estados Unidos ou à União Europeia, porque estes inventaram e plasmaram a globalização". O emparelhamento de estratégias de desenvolvimento dos PEDs ajuda a compreender "como estão resolvendo seus problemas de inserção" (Ricupero, 2002:36).

\section{O FÓRUM IBAS: ESTRUTURA ORGANIZACIONAL E MECANISMOS DE ARTICULAÇÃO INTERGOVERNAMENTAL E DE COORDENAÇÃO INTRAGOVERNAMENTAL}

Para a definição e implementação das diretrizes de ação do Fórum IBAS, foram criadas três instâncias principais de articulação intergovernamental entre os três países-membros, quais sejam: (a) a de articulação entre os Chefes de Estado, por intermédio das Cúpulas Presidenciais, principalmente; (b) as Comissões Mistas Trilaterais, que organizam a interação entre os ministérios temáticos dos três países, por intermédio dos Encontros Ministeriais; e (c) a dos chamados Pontos Focais, que são oficiais seniores responsáveis pela coordenação institucional das atividades dos Grupos de Trabalho e pelas ações de concer- 
tação política dos Chanceleres e dos Chefes de Estado, bem como por gerenciar as atividades do Fundo IBAS. Para dar maior capilaridade doméstica à busca de cooperação trilateral, foram criados também grupos específicos de trabalho (os GTs), que se dedicam aos temas prioritários definidos no Guia de Ações, estabelecido em 2004, cujo objetivo é possibilitar a troca de informações e facilitar as interações e a cooperação técnica entre as burocracias dos países-membros.

Antes de examinarmos os mecanismos e dinâmicas que têm sido adotados para a implementação doméstica, no Brasil, das diretrizes de atuação do IBAS, ou seja, as formas de articulação intragovernamental para a concretização dos objetivos propostos, cabe comentarmos, brevemente, o funcionamento destas três instâncias de articulação intergovernamental. Na base desta estrutura de articulação intergovernamental, que conecta lideranças políticas e parte do aparato burocrático-administrativo dos países-membros, encontram-se os Pontos Focais, que são altos funcionários da Chancelaria dos três países, responsáveis pela supervisão dos GTs, que serão discutidos adiante, e de seu adequado funcionamento, seguindo as prioridades e cursos de ação definidos nas duas instâncias superiores da hierarquia. Os Pontos Focais de cada um dos países se reúnem regularmente, buscando a harmonização e o gerenciamento das atividades do Fórum, de modo a monitorar e aprimorar o intercâmbio e garantir a evolução do diálogo e da cooperação entre as partes. Para tanto, foram realizadas, até abril de 2009, quatorze reuniões dos Pontos Focais.

Os Encontros de Chanceleres (ou Comistas) ocorrem no mínimo uma vez ao ano (sendo normalmente realizados no primeiro semestre, preliminarmente às Cúpulas Presidenciais) e são fundamentalmente baseados nas Reuniões de Pontos Focais, que verificam previamente os pontos de interesse para o aprimoramento da concertação política entre as partes. Nesses encontros são debatidos temas de interesse global como: comércio, clima, desenvolvimento e gênero, além de questões regionais e outros assuntos inerentes ao Fórum IBAS, como o andamento das atividades do Fundo IBAS. Nessas ocasiões, normalmente são apresentados documentos oficiais, denominados Comunicados Ministeriais, que resumem as propostas de atuação do Fórum IBAS em âmbito global e regional, em termos de cooperação técnica e política.

O nível mais alto da hierarquia do IBAS é o das Cúpulas Presidenciais. Tais reuniões têm sido realizadas anualmente desde 2006, quando os 
presidentes dos três países se encontraram em Brasília. Nesses encontros são assinados os acordos de cooperação entre as partes e os três Chefes de Estado pronunciam-se sobre o futuro do Fórum e sobre o seu posicionamento perante os principais acontecimentos do sistema internacional de seu interesse mais imediato e sobre temas globais e/ou regionais, além de explicitarem os objetivos de longo prazo para o Fórum. Após cada encontro é publicada uma declaração oficial, contendo as projeções futuras para a cooperação entre as partes.

Para a concretização das diretrizes definidas no âmbito intergovernamental, foi fundamental a criação e institucionalização de mecanismos de coordenação no plano intragovernamental, em cada um dos países-membros. Interessa-nos neste artigo compreender a maneira como o Brasil, buscando implementar os cursos de ação definidos, procura reconfigurar a sua estrutura burocrática para a efetivação da cooperação trilateral no âmbito do Fórum IBAS. A implementação das diretrizes de cooperação demanda mudanças organizacionais para a dinamização da coordenação das ações no plano intragovernamental, notadamente por meio da criação dos Grupos de Trabalhos (GTs).

No caso brasileiro, a institucionalização inicia-se em 2004, com a designação de um diplomata como responsável pela coordenação das ações do IBAS nos âmbitos doméstico e internacional. Foi criada uma coordenação específica das atividades do Fórum, dentro do organograma do MRE, qual seja, a Coordenação do Fórum de Diálogo Índia-Brasil-África do Sul (CIBAS), regulamentada pelo Decreto no 5.979, de dezembro de 2006, que era parte da Subsecretaria Geral Política II (SGAP II), do MRE. No entanto, o progressivo fortalecimento da iniciativa, o incremento da cooperação e a ampliação das áreas de ação do Fórum exigiram do governo brasileiro uma estrutura ainda mais robusta. Em 2008, para substituir a CIBAS, foi criada a Divisão do Fórum Índia, Brasil e África do Sul (DIBAS), responsável pela coordenação das ações do Fórum IBAS, que estava subordinada ao Departamento de Mecanismos Regionais (DMR), ainda sob a égide institucional da SGAP II. Em 2010, o DMR transformou-se em Departamento de Mecanismos Interregionais e a DIBAS transformou-se em Divisão do Fórum IBAS e Agrupamento BRICs.

Desde o fim da Guerra Fria, e com a mudança no paradigma de inserção internacional do Brasil, no início da década de 1990, tem havido significativas alterações na estrutura organizacional do Itamaraty, 
com a criação, fusão e/ou expansão de Coordenações, Divisões e Departamentos (ver o trabalho de Puntigliano, 2008). As constantes reformulações na estrutura do MRE refletem, assim, não apenas as inflexões da política externa brasileira, mas também as alterações no seu modo de ação e a multiplicação das relações internacionais do país. A criação da DIBAS, menos de dois anos após o surgimento da CIBAS, com a consequente ampliação do quadro funcional do MRE dedicado ao IBAS, reflete, por certo, a própria dinamização do Fórum neste período.

Até 2007, a CIBAS contava com apenas um diplomata, responsável pelo trabalho de articulação doméstica para a implementação das ações de cooperação no âmbito do Fórum, a quem se somava o Ponto Focal no Brasil. Em fevereiro de 2008, a DIBAS, que substitui a CIBAS, passou a ser composta por três diplomatas. Em julho do mesmo ano, juntou-se à equipe mais um diplomata, que exerceria a chefia da DIBAS. Em 2009, foram agregados mais três servidores, sendo um designado para assumir a Subchefia da Divisão, e dois novos estagiários substituíram os antigos, que agora estão efetivamente lotados na DIBAS. Assim, em meados de 2009 o quadro funcional do MRE dedicado ao IBAS era composto por seis pessoas, sendo quatro diplomatas efetivamente lotados na DIBAS e mais dois estagiários do IRBr, auxiliados pelos da DMR, além do próprio Chefe do Departamento, que era o Coordenador Nacional Brasileiro do IBAS, somado ainda ao Ponto Focal Brasileiro, lotado na SGAP II. Cabe destacar, porém, que outros funcionários lotados na SGAP II e na DMR também auxiliam nas atividades do IBAS, no plano administrativo.

A SGAP II, segundo o artigo 16 do Decreto no 5.979, de 6 de dezembro de 2006, é a Subsecretaria responsável por assessorar o secretário-geral de Relações Exteriores nas questões de política exterior de natureza bilateral, birregional e multilateral com os países ou o conjunto de países das áreas geográficas por ela abrangidas, quais sejam, Ásia, África, Oceania e Oriente Médio. A DIBAS, que funciona como instituição coordenadora brasileira do Fórum IBAS, foi instituída, em janeiro de 2008, pela Circular Telegráfica no 66.881, dentro da estrutura da SGAP II, justificando-se, desse modo, a escolha do subsecretário geral de Política II como Ponto Focal do IBAS no Brasil. No mesmo sentido, justifica-se a escolha do chefe do DMR como Coordenador Nacional do IBAS no Brasil, uma vez que a DIBAS está subordinada ao DMR. 
Em 2010, a DIBAS transformou-se em DIB, agregando também o agrupamento BRIC, uma vez que são coincidentes os países participantes lembrando que em 2011 a África do Sul foi incorporada ao BRICs.

Entre 2010 e 2011, verificou-se uma diminuição no efetivo diplomático para tratar desses mecanismos, restando, em abril de 2011, o Chefe da divisão, diplomata responsável pelo Fórum IBAS e Aglomerado BRIC, e mais três diplomatas lotados para auxiliá-lo.

Tanto o Ponto Focal como o Coordenador Nacional do IBAS no Brasil são altos funcionários do MRE, responsáveis pela articulação e gestão das atividades do Fórum tanto no plano doméstico quanto pelas interações com os outros dois Estados membros. O Ponto Focal e o Coordenador Nacional do IBAS são responsáveis por assessorar o ministro das Relações Exteriores e o presidente da República no que concerne ao IBAS, por monitorar as atividades dos Grupos de Trabalho, preparar encontros ministeriais e presidenciais, além de verificar o andamento das políticas desenvolvidas pelo Fórum IBAS em outros países, por intermédio das atividades do Fundo IBAS $^{3}$.

Auxiliam, ainda, na execução das ações do IBAS as diversas Divisões e Departamentos do MRE envolvidos nos vários Grupos de Trabalho. As informações sobre as ações desenvolvidas pelo Fórum IBAS são mantidas atualizadas e disponíveis no sítio eletrônico da DIB ${ }^{4}$ e de outras Divisões, bem como nas páginas eletrônicas dos Ministérios e de outros órgãos envolvidos nas atividades do Fórum.

As Embaixadas do Brasil, localizadas em Nova Déli e Pretória, também contribuem ativamente, fazendo a intermediação da Chancelaria brasileira com seus pares nos outros dois membros do Fórum. Colaboram, ainda, os Consulados localizados em outras cidades da África do Sul e da Índia, como o da Cidade do Cabo e o de Mumbai.

Em um nível hierárquico inferior da estrutura organizacional do Fórum IBAS, encontram-se os dezesseis GTs, que são gerenciados, em cada um dos três países, pelos Pontos Nodais. Estes são funcionários de alto escalão da burocracia federal, podendo ser lotados no próprio MRE ou em órgãos federais, ou outros ministérios. Os Pontos Nodais atuam como coordenadores domésticos dos GTs, fazendo, além do gerenciamento doméstico das atividades, a coordenação das interações intergovernamentais dos Grupos. 
A escolha do Ponto Nodal é feita a partir das atividades desenvolvidas por cada GT, ou seja, caso as políticas trabalhadas nos GTs estejam sob responsabilidade principal de um órgão federal ou ministério específico, espera-se que o Ponto Nodal seja, portanto, um funcionário lotado neste órgão ou ministério; caso as ações desenvolvidas pelo GT estejam relacionadas mais diretamente ao MRE, o Ponto Nodal deverá ser proveniente do MRE. Tal escolha tem por objetivo facilitar tanto o relacionamento entre as instituições envolvidas nos GTs quanto aproximar as burocracias dos outros dois países envolvidos no IBAS, uma vez que as ações dos GTs, para serem implementadas, necessitam da cooperação intragovernamental e intergovernamental.

Cada um dos dezesseis Grupos de Trabalho do IBAS é formado por representantes dos três países, existindo, pois, um único GT do IBAS para cada uma das áreas em que se busca a cooperação, do qual participam representantes dos três países.

Conforme anteriormente anunciado, para cada GT há um Ponto Nodal em cada um dos países, que é o responsável pela articulação doméstica em cada país, bem como pela coordenação entre as delegações dos outros dois países-membros. Cabe, no entanto, diferenciar os Pontos Nodais dos coordenadores ad hoc que são escolhidos em cada encontro trilateral dos GTs, momento em que estão presentes representantes dos três países. Isso ocorre para facilitar o andamento do encontro, bem como para possibilitar o secretariado da reunião, de modo que seja possível a produção de uma ata final, na qual estarão definidos os projetos a serem executados.

Os Pontos Nodais brasileiros coordenam as atividades dos GTs no plano doméstico, intragovernamental, e as interações, na temática objeto de cada GT, com as outras duas delegações da Índia e da África do Sul, devendo, ainda, manter a DIBAS informada acerca de todas as atividades dos grupos.

Cabe destacar que alguns dos GTs mantêm atividades que envolvem a sociedade civil (especialmente no Fórum entre Povos), como ocorre no GT de Comércio e Investimentos, que está sempre em contato com o Fórum Empresarial do IBAS, cuja coordenação no Brasil é feita através da Confederação Nacional das Indústrias (CNI), bem como com o Fórum de Pequenas Empresas, que reúne as instituições que gerenciam as atividades das pequenas empresas nos três países (no Brasil, o Sebrae); na África do Sul, a Small Enterprise Development Agency 
(SEDA); e na Índia, a National Small Industries Corporation Ltd. (NSIC).

A cooperação entre e no interior dos três países funciona de modo independente em cada uma das áreas definidas nos GTs, como especificado nos Memorandos de Entendimentos ${ }^{5}$ assinados pelos três países, bem como nos planos de ações definidos e implementados por cada GT, que agem de modo particular, com ritmos e estratégias próprias de ação. Esse fato se explica pelos diferentes tipos de cooperação desenvolvidos por cada um dos GTs. A atuação dos GTs tem, algumas vezes, implicação mais direta na sociedade, enquanto em outros casos ela demanda alteração legal, o que resulta em distintos processos, envolvendo ritmos igualmente variados.

As diversas instâncias de concertação política, relativas aos três níveis institucionais, reúnem-se periodicamente, e mesmo sem uma estrutura supranacional, como uma Secretaria Geral ou mesmo uma Presidência, no IBAS convencionou-se a existência de uma secretaria informal, gerida por cada um dos países num revezamento anual, ou seja, a cada ano um país fica responsável pela realização de encontros ministeriais e cúpulas presidenciais.

Se neste artigo a nossa preocupação central é com a cooperação intragovernamental, no Brasil, para a implementação das diretrizes do IBAS, cabe mencionarmos, brevemente, o papel dos agentes societários nesta estrutura, para além da participação de alguns grupos de interesse nos GTs, como será ressaltado abaixo. Buscando expandir o processo de aproximação entre os países e com o objetivo de incrementar a participação da sociedade civil no Fórum IBAS, as chancelarias dos três países conceberam ações que envolvem entidades e organizações de fora da esfera governamental. Destacam-se algumas iniciativas, que se tornaram permanentes, devido às suas sucessivas edições, como os Fóruns de Mulheres, Acadêmico, Empresarial, de Parlamentares e de Editores.

\section{MECANISMOS E PROCESSOS DE COORDENAÇÃO INTRAGOVERNAMENTAL PARA A IMPLEMENTAÇÃO DE POLÍTICAS PÚBLICAS}

Na presente seção, nosso objetivo é explicitar, de maneira quase telegráfica, os processos que levaram à fragmentação do planejamento e da gestão no setor público; os fatores que têm gerado a pressão para o 
rompimento deste padrão inercial; as dificuldades e barreiras à coordenação entre as agências estatais ${ }^{6}$; e os mecanismos mais frequentemente adotados para a produção da coordenação intragovernamental.

A definição de "coordenação" proposta por Alexander parece-nos pertinente neste nosso esforço analítico: "[...] coordenação é definida como uma atividade deliberada, por parte de uma organização ou um sistema interorganizacional, para fazer convergirem as decisões e ações das suas subunidades ou organizações membro. Essa coordenação manifesta-se tanto no processo como na estrutura" (Alexander, 1993:331).

Inicialmente, é necessário que fique claro que a preocupação com a coordenação intragovernamental é um fenômeno relativamente antigo. Como sugerido por Guy Peters, desde o tempo em que as estruturas governamentais começaram a se diferenciar, com a criação de uma variedade de ministérios e departamentos, muitos têm afirmado que uma agência desconhece o trabalho realizado pelas outras e que os seus programas são contraditórios, redundantes ou ambos (Peters, 1998:295).

Processos de distinta natureza têm sido responsáveis pela fragmentação do planejamento e da gestão no setor público. Dentre eles, talvez sejam os seguintes aqueles que mais diretamente têm obstaculizado a capacidade de coordenação das agências estatais: (a) o fato de os governos terem progressivamente ampliado o leque de suas atribuições; (b) os processos de descentralização, devolução e/ou privatização; (c) o aumento da complexidade e do caráter técnico de parte significativa dos assuntos e questões com as quais se defronta o Estado; (d) as diretrizes de reforma do Estado, amplamente adotadas nas décadas de 1980 e 1990, que via de regra se espelharam no funcionamento das organizações do mercado e/ou buscaram a ampliação da participação dos cidadãos ou "clientes". Como afirma Peters, esse "foco nos clientes e nos servidores no interior de uma única organização torna menos provável a coordenação" (ibidem:296).

Os fatores que têm gerado a pressão para o rompimento do padrão inercial de planejamento e gestão, em geral fragmentado, podem ser sintetizados da seguinte maneira: (a) os recorrentes problemas fiscais com os quais têm se deparado os governos, os quais, somados às crescentes demandas por eficiência, transparência e accountability, fazem com que a coordenação seja percebida como uma forma aparentemen- 
te simples de se eliminar a redundância e a inconsistência dos programas governamentais; (b) ainda que a visão prevalecente destaque a tendência das organizações em geral e das burocracias públicas muito particularmente de preservar ou de buscar a ampliação de suas próprias prerrogativas, de sua autonomia e de seus orçamentos, alguns outros fatores parecem operar no sentido do fomento à coordenação, tais como: a definição do papel do técnico/profissional e a ênfase dada aos beneficiários/clientes, os quais sentiriam em primeiro lugar o impacto positivo de tal mudança no comportamento das organizações e de seus profissionais (ibidem:305); (c) por fim, o reconhecimento de que a complexificação dos processos sociais tornou obsoletas e ultrapassadas determinadas concepções que informavam o planejamento governamental.

Contudo, são diversas as dificuldades e barreiras à coordenação entre as agências públicas. Jennings Jr. e Krane (1994) sugerem a necessidade de reconhecermos a existência de barreiras organizacionais, legais/técnicas e políticas. As barreiras de ordem organizacional estariam relacionadas às distintas missões, orientações profissionais, estruturas e processos das agências públicas. As várias missões e orientações profissionais incidem sobre a definição dos objetivos e das prioridades das organizações, podendo levar a divergências acerca da maneira mais adequada de se atingir os fins propostos, o que, obviamente, pode dificultar a ação coordenada entre diferentes agências. Há também a possibilidade de que as organizações possam ignorar ou desconfiar do modo de operação e das finalidades das outras agências. No que diz respeito às estruturas e aos processos, obstáculos à cooperação podem ser derivados da limitação das conexões interorganizacionais, reproduzida por distintas estruturas e processos e pela eventual necessidade de que a aprovação de vários níveis da organização seja requerida e/ou pela existência de uma diversidade de "pontos de veto". Ademais, a abrangência geográfica da provisão de serviços pode variar, podendo também haver incompatibilidade nos procedimentos e nos sistemas de incentivo.

As barreiras legais e técnicas à coordenação podem se originar da própria circunscrição, definida pela legislação pertinente, para a atuação da agência, assim como de regulamentos internos emanados dos escalões mais elevados das organizações e também da distinta capacitação tecnológica e da experiência acumulada das agências. Destacam-se aqui as restrições legais à utilização dos recursos financeiros e técnicos 
das organizações e a possibilidade de conflito entre as regulamentações dos vários níveis de governo.

Como também destacado por Jennings Jr. e Krane (1994), as barreiras políticas à coordenação podem estar lastreadas tanto no ambiente político externo às políticas e programas, quanto na "política" interna da própria burocracia. No que diz respeito às disputas intraburocráticas e à política da burocracia, o conhecido termo "proteção do território" (turf protection) parece sintetizar com precisão um comportamento já amplamente estudado. A ideia expressa é que cada organização tem a sua área de atuação definida, hegemonia essa que ela vai lutar para preservar (ou ampliar), procurando excluir competidores potenciais, mesmo (ou principalmente) sendo eles outras organizações governamentais. Dito de outra forma, para que esta "hegemonia" seja preservada sobre o território, sobre uma clientela, sobre uma questão ou problema ou sobre uma dada forma de atuação, o comportamento esperado é a competição, não a cooperação.

As barreiras políticas externas, por sua vez, são também de várias ordens: podem ser oriundas de grupos de pressão que desejam proteger os seus interesses na produção da política pública; podem estar relacionadas a estruturas e processos do Legislativo que têm incidência sobre a fragmentação das agências e das políticas ou programas, sendo também possível que o Legislativo faça valer o seu interesse em privilegiar programas de maior visibilidade ou do interesse de alguns de seus atores mais relevantes. Ademais, é crucial o apoio das lideranças do Executivo às diretrizes de coordenação.

Por fim, cabe-nos apresentar, muito sinteticamente, os mecanismos mais frequentemente adotados para a produção da coordenação intragovernamental. Em sua apresentação de um arcabouço conceitual para a compreensão da coordenação interorganizacional, Alexander (1993) nos alerta para a necessidade de distinguirmos as estruturas de coordenação dos instrumentos de coordenação. De acordo com o autor:

As estruturas de coordenação representam as formas surgidas entre as organizações (no caso das redes informais) ou que foram designadas ou estruturadas (no caso das estruturas formais de coordenação) [como as que estamos analisando neste trabalho] para produzir a coordenação interorganizacional. Elas são os mecanismos de ligação que transformam campos ou redes interorganizacionais descoordenados ou menos coordenados em campos ou redes mais coordenados. Os instru- 
mentos de coordenação são os elementos específicos da ação, interação ou comportamento organizacional que permitem a coordenação interorganizacional. Reuniões ou contatos telefônicos são exemplos de instrumentos das articulações informais; contratos ou budget sign-off são exemplos de instrumentos formais. Os instrumentos da coordenação interorganizacional lidam com os três problemas básicos de coordenação: retroalimentação (feedback), orientação e controle (Alexander, 1993:339-340)

Na Figura 1, reproduzimos, em sua completude, a proposta, feita por Alexander, de um arcabouço conceitual para a compreensão da Coordenação Interorganizacional, que, contudo, não será plenamente explorado neste artigo:

Figura 1

Arcabouço Conceitual para a Compreensão da Coordenação Interorganizacional

\begin{tabular}{|c|c|c|c|}
\hline \multirow[b]{2}{*}{ Informal } & $\begin{array}{l}\text { + CONCRETO } \\
\text { Ferramentas de } \\
\text { coordenação }\end{array}$ & $\begin{array}{l}\text { Estruturas de } \\
\text { coordenação }\end{array}$ & $\begin{array}{c}\rightarrow+\text { ABSTRATO } \\
\text { Redes } \\
\text { Interorganizacionais }\end{array}$ \\
\hline & $\begin{array}{l}\text { Conexões informais } \\
\text { - Ligações telefônicas } \\
\text { - Correspondência } \\
\text { - Reuniões }\end{array}$ & Rede Informal & Ambiente "Feudal" \\
\hline Formal & $\begin{array}{l}\text { Governança conjunta / } \\
\text { Reunião de Conselho } \\
\text { Planejamento conjunto } \\
\text { Revisão de Projetos / } \\
\text { aprovação } \\
\text { Revisão de orçamento / } \\
\text { assinatura } \\
\text { Colocação } \\
\text { Contrato / acordo } \\
\text { Estatutos, regulamentos, } \\
\text { ordenamentos }\end{array}$ & $\begin{array}{l}\text { Grupo } \\
\text { Interorganizacional } \\
\text { Coordenador } \\
\text { Unidade de } \\
\text { Coordenação } \\
\text { Programa não } \\
\text { administrado } \\
\text { Organização líder } \\
\text { Organização unitária }\end{array}$ & $\begin{array}{l}\text { Ambiente "Mediado" } \\
\text { • "Organização } \\
\text { mutua" } \\
\text { • Empreendimento } \\
\text { conjunto } \\
\text { - Aliança } \\
\text { • Federação } \\
\text { Ambiente "dirigido" } \\
\text { - Império Corporativo }\end{array}$ \\
\hline
\end{tabular}

Fonte: Alexander (1993:340).

Como forma de apresentação sucinta dos mecanismos de coordenação possíveis, complementando a proposta de Alexander de uma forma mais simples, reproduzimos abaixo os mecanismos arrolados por Regens (1988): 
Quadro 1

Tipos de Mecanismos de Coordenação

\begin{tabular}{|l|l|l|}
\hline $\begin{array}{l}\text { Interconexões a partir de } \\
\text { baixo }\end{array}$ & $\begin{array}{l}\text { Autoconexões entre } \\
\text { funcionários }\end{array}$ & $\begin{array}{l}\text { Orquestração a partir de } \\
\text { cima }\end{array}$ \\
\hline $\begin{array}{l}\text { Intercâmbio informal de } \\
\text { informações }\end{array}$ & $\begin{array}{l}\text { Intercâmbio formal de } \\
\text { informações, clearing } \\
\text { houses }\end{array}$ & $\begin{array}{l}\text { Agência uni-integrada } \\
\text { (single integrated) }\end{array}$ \\
\hline Reuniões periódicas & Conselhos consultivos & $\begin{array}{l}\text { Agência } \\
\text { principal/coordenadora }\end{array}$ \\
\hline \multirow{2}{*}{$\begin{array}{l}\text { Projetos ad hoc, acordos } \\
\text { projeto-por-projeto }\end{array}$} & Forças-tarefa & Mandatos estatutários \\
\cline { 2 - 3 } Copresença de escritórios & $\begin{array}{l}\text { Memorandos de } \\
\text { entendimento }\end{array}$ & monitoramento seletos de \\
\cline { 2 - 3 } & & \\
\hline
\end{tabular}

Fonte: Regens (1988:148).

Antes de nos dedicarmos, na próxima seção, à análise das estruturas, dinâmicas e processos da coordenação intragovernamental para a implementação, no Brasil, das diretrizes do Fórum IBAS, cabe reiterarmos que a seção que aqui se encerra teve o objetivo de sinalizar, brevemente, para a complexidade dos processos de coordenação. No que se segue, várias das barreiras à coordenação, por exemplo, deveriam ser analisadas para que pudéssemos produzir uma apreciação menos sumária dos processos e estruturas em questão.

\section{ESTRUTURAS, DINÂMICAS E PROCESSOS DA COORDENAÇÃO INTRAGOVERNAMENTAL PARA A IMPLEMENTAÇÃO, NO BRASIL, DAS DIRETRIZES DO FÓRUM IBAS}

Antes de nos determos, mais especificamente, na apresentação dos Grupos de Trabalho do IBAS, serão classificadas as estruturas de coordenação intragovernamental instituídas. Se o nosso foco recairá, nesta seção, sobre o funcionamento dos GTs, o complexo arranjo adotado para a implementação da cooperação trilateral no âmbito doméstico deve ser mencionado, ainda que sumariamente (ver também a Figura 1$)$.

(a) Secretaria Intergovernamental do IBAS - Institucionalizada de maneira não formal pelos três países que conformam o IBAS. Os Estados-membros decidiram, de forma consensual, que a cada ano um dos membros será responsável pela coordenação das atividades do IBAS, como se ocupasse a presidência do Fórum. Nesse sentido, por não ser 
uma estrutura formalizada, considera-se que esta secretaria rotativa pode ser pensada como um "programa não administrado", como definido por Alexander (1993). Esta é vista pelo autor como a mais simples estrutura de coordenação de uma rede interorganizacional, sendo que tal estrutura raramente é encontrada exercendo sozinha a coordenação, posto que é sempre respaldada por outras estruturas de coordenação interorganizacional, a exemplo do que ocorre no Fórum IBAS. Entretanto, cabe sugerir que a Secretaria do IBAS também pode ser pensada, ainda segundo as categorias propostas por Alexander, como equivalente às "redes informais", pois esse tipo de rede dá suporte às demais estruturas de coordenação, utilizando-se de instrumentos diversos.

(b) DIB - Em função da complexidade e do caráter multifacetado das ações realizadas pela DIB, essa Divisão do Itamaraty pode ser vista como equivalente, em sua atuação como coordenadora geral das atividades do IBAS, como uma "organização líder", ainda segundo as categorias de Alexander (1993). Para esse autor, a "organização líder" representa um arranjo em que uma organização assume as responsabilidades pela coordenação das atividades de uma rede interorganizacional, sendo dotada de um status especial perante as outras organizações parceiras, tendo ainda responsabilidades funcionais. Todavia, parte da implementação pode ser responsabilidade de outras organizações da rede, como fica evidente quando se estudam as atividades desenvolvidas pelos dezesseis Grupos de Trabalho do IBAS ou a implementação das atividades do Fundo IBAS. "A organização líder é uma estrutura de coordenação de nível mais alto. Ela representa um quadro geral (overall framework) de relações institucionais entre os participantes principais de um sistema interorganizacional, mais do que o mecanismo detalhado por intermédio do qual o processo decisório concertado é atingido" (Alexander, 1993:338).

(c) Ponto Focal - As funções do Ponto Focal podem ser comparadas às de uma "unidade de coordenação", já que ela existe para coordenar e implementar decisões relevantes para o sistema interorganizacional, sendo distinta do grupo interorganizacional por sua maior autonomia. "A unidade de coordenação não tem qualquer função 'de linha' nem implementa qualquer das tarefas que cabe a ela coordenar" (Alexander, 1993:336). Sendo o Ponto Focal uma ponte entre o setor político, o ministro das Relações Exteriores e o presidente da República, por um lado, e o setor técnico dos GTs, por meio da DIB, por outro, parece-nos 
possível pensar que o Ponto Focal exerce funções e tem características semelhantes às de uma "unidade de coordenação".

(d) Coordenador Nacional - O Coordenador Nacional do IBAS é um diplomata, designado para gerenciar as atividades do MRE relativas ao Fórum, que se mantém a par das atividades dos GTs desde o início, sendo o principal elo de articulação intragovernamental do IBAS. Cabe ao coordenador nacional esse papel de articulação política intragovernamental.

(e) Ponto Nodal - A função de coordenação do Ponto Nodal equivale à do "coordenador", como descrita por Alexander (1993). Segundo este autor, esta é uma estrutura utilizada em combinação com outras formas de coordenação, sendo apenas um instrumento de concertação interorganizacional para tomada de decisões. No funcionamento dos GTs, o Ponto Nodal é, sem dúvida, este instrumento de concertação entre as diferentes entidades envolvidas no Grupo de Trabalho em âmbito doméstico, como também entre os representantes do GT nos outros dois Estados membros. Para tanto, conforme afirma Alexander (1993), a personalidade, a qualificação e o comprometimento burocrático são importantes fatores que influenciam o sucesso do coordenador.

Dois fatores independentes parecem relacionados à efetividade de um coordenador. Um é a personalidade individual, as qualificações do indivíduo e o seu engajamento nesta atividade que atravessa fronteiras (boundary-spanning role). O outro é a maneira como o seu papel está estruturado na rede interorganizacional (Alexander, 1993:336).

No caso do IBAS, a localização burocrática do Ponto Nodal pode se somar às características apresentadas por Alexander (1993), uma vez que, estando este burocrata diretamente envolvido com o MRE, terá as diretrizes da política externa como linha prioritária de ação para implementação da cooperação mais técnica do IBAS. De outro modo, poderiam ser mais frequentes os conflitos entre os interesses domésticos mais particulares de cada um dos agentes governamentais, em detrimento das ações de cooperação internacional mais diretamente definidas pelo Itamaraty.

(f) Grupos de Trabalho - Parece inquestionável que, como estruturas de coordenação, os GTs do IBAS possam ser classificados, segundo as categorias de Alexander, como "grupos interorganizacionais". "Os grupos interorganizacionais podem se tornar realidade a partir da rotini- 
zação de reuniões ou dos grupos de trabalho e em resposta à necessidade de se solucionar problemas correntes derivados de interdependências reais ou percebidas" (Alexander, 1993:335).

Formados por diferentes agentes governamentais, distribuídos horizontalmente no organograma do governo federal, os GTs preenchem, deste modo, um segundo requisito apresentado por Alexander (1993), o de que os "grupos interorganizacionais" devem ser utilizados para coordenação horizontal entre agências.

Os GTs concentram, tanto no plano intergovernamental como no intragovernamental, as atividades setoriais de cooperação/coordenação do Fórum IBAS, chamado Fórum de Diálogo, o qual pretende incentivar e ampliar a cooperação entre os três países-membros. Assim, os GTs têm por função desenvolver ações concretas de implementação das diretrizes de cooperação estabelecidas nas instâncias de articulação política da IBAS. Eles foram criados com o intuito de gerar um maior intercâmbio de experiências e práticas governamentais, possibilitando a execução de ações conjuntas. Atualmente são dezesseis os Grupos de Trabalho do IBAS. Este número, porém, não é fixo, existindo hoje propostas de criação de outros grupos e de reestruturação daqueles já implantados.

Em cada um dos GTs podem existir subgrupos, que são especializações do tema central do GT, como, por exemplo, o de Educação, que conta com o subgrupo de cooperação esportiva e um de cooperação entre academias diplomáticas. O de Agricultura tem os subgrupos de saúde animal, de medidas sanitárias e fitossanitárias, de agroprocessamento, de políticas públicas e pesquisa e de capacitação. No GT de Ciência e Tecnologia há o subgrupo de pesquisa antártica. Ainda que se estude hoje a possibilidade de ampliação do número de GTs, há um consenso entre os países que neste momento importa mais fortalecer as parcerias existentes do que ampliar o número de áreas de trabalho. Portanto, alguns dos novos temas a serem inseridos para cooperação entre as partes têm sido incorporados como subgrupos dos GTs já existentes.

Cada GT funciona de maneira autônoma, tendo seu próprio ritmo de trabalho e formas de atuação. Cabe, ainda, considerar as diferenças estruturais das burocracias dos três Estados, uma vez que o andamento dos trabalhos nos GTs pode ser obstaculizado ou facilitado pelas especificidades do aparato burocrático-administrativo específico de cada país e setor de atuação. Todos os GTs encontram-se em um mesmo ní- 
vel hierárquico dentro da estrutura organizacional do IBAS, não havendo participação direta das instâncias políticas no funcionamento dos GTs. Em cada país há um coordenador nacional para cada GT, que são os chamados Pontos Nodais. Estes são funcionários de um dos órgãos governamentais envolvidos no GT naquele país, designados para facilitar o acompanhamento e a implementação das atividades do Grupo.

No entanto, segundo telegramas e outras correspondências trocadas pelos três países, além de atas e declarações oficiais dos três Estados, há dificuldades de coordenação e acompanhamento das atividades dos grupos, devido ao grande número de instituições envolvidas, bem como em razão da priorização de interesses próprios por parte de cada um dos órgãos envolvidos. Para facilitar este gerenciamento, foi proposta a criação de três grandes clusters ou comissões, nas quais os GTs estariam divididos por áreas de atuação, sendo que a coordenação de cada uma dessas comissões ficaria a cargo de um dos países, por um período determinado, havendo rotatividade periódica das responsabilidades. Todavia, tal proposta ainda vem sendo debatida nas reuniões do IBAS.

Segundo uma proposta apresentada pelo Brasil, tais clusters seriam divididos da seguinte maneira: (a) Temas Sociais, o que incluiria os GTs de Administração Pública, Assentamentos Humanos, Cultura, Desenvolvimento Social, Educação, Saúde e os que posteriormente possam ser criados; (b) Temas Econômicos, englobando os GTs de Administração Tributária e Aduaneira, de Comércio e Investimentos, de Transportes, de Turismo e de Sociedade da Informação; e (c) Temas de Recursos Naturais, envolvendo Agricultura, Ciência e Tecnologia, Defesa, Energia e Meio Ambiente.

Os GTs mantêm encontros periódicos, de modo a controlar melhor suas ações e definir planos de ações a serem implementados em cada um dos países ou nos três Estados simultaneamente. Os encontros podem ocorrer tanto em paralelo a eventos multilaterais de organizações internacionais sobre temas mais específicos, quanto durante os eventos gerais do IBAS, como reuniões de Pontos Focais, Comistas ou Cúpulas Presidenciais.

Os três países participantes do IBAS têm representação em todos os dezesseis GTs. No Brasil, que nos interessa particularmente, os participantes são tanto funcionários do MRE quanto de outros ministérios e demais órgãos federais. Como nem sempre o MRE tem departamentos 
ou especialistas nas áreas de atuação dos GTs, o acompanhamento das atividades dos grupos fica, então, em alguns casos, sob a responsabilidade de outro ministério ou órgão federal, como exemplificado pelo GT de Administração Pública. Também existem GTs que não mantêm correspondentes nos órgãos e ministérios, ficando as atividades do grupo sob responsabilidade apenas do MRE. No caso do GT de Cultura, mesmo existindo um Ministério específico, não há neste órgão um funcionário designado para tratar especificamente dos assuntos do IBAS, sendo o seu Ponto Nodal, portanto, lotado no Itamaraty. Os outros GTs, além de contarem com representantes do MRE, contam com representantes de órgãos ou de outros ministérios, atuando todos em conjunto para a implementação das políticas do Fórum IBAS.

Existe um Ponto Nodal para cada GT, que é um funcionário designado para representar o GT em encontros trilaterais. Eles também gerenciam as atividades dos Grupos, além de atuarem na interlocução dos órgãos envolvidos nas atividades do GT, bem como dos representantes dos outros dois Estados participantes do Fórum. Constata-se uma certa independência na atuação dos GTs, uma vez que há uma interlocução direta feita com os grupos e seus representantes em cada um dos países, havendo também autonomia dos grupos para decidir sobre os prazos e o modo de implementação de políticas e para marcar encontros e atividades do GT, sem maiores interferências externas.

A seguir serão descritas e analisadas, de forma bastante sucinta, as atividades dos dezesseis Grupos de Trabalho, apresentados por ordem alfabética $^{7}$. Serão enfatizadas, por óbvio, as questões relativas à implementação da iniciativa IBAS por parte do Estado brasileiro.

\section{(1) Administração Pública}

Como parte das atividades de implementação das políticas de cooperação entre os três Estados na temática de administração pública, além do Memorando de Entendimento, que já foi assinado pelos países, mas ainda não entrou em vigor, aguarda-se atualmente a aprovação pelos outros países da minuta do Estatuto do IBAS sobre Administração Pública, que, como vimos, está sob a responsabilidade do Brasil.

Ainda no sentido de implementar ações efetivas de cooperação na área, foi realizado em São Paulo e em Brasília, pela Escola Nacional de Administração Pública (ENAP), em setembro de 2008, o Seminário “Práticas Sul-Sul em Gestão de Escolas de Governo, Desenvolvimento 
de Dirigentes e Prestação de Serviços ao Cidadão", do qual participaram as escolas de administração pública dos três países: a ENAP do Brasil; a Administrative Staff College of India (ASCI), da Índia; e a Public Administration Leadership and Management Academy (Palama), da África do Sul. O objetivo do evento foi dar início ao intercâmbio de experiências, possibilitando a efetiva cooperação regional.

O Ponto Nodal do GT de Administração Pública encontra-se no Ministério do Planejamento, Orçamento e Gestão (MPOG), por não haver contraparte dentro das divisões do MRE, ficando a cargo da própria DIB a tarefa de articulação com o MPOG para a implementação das ações do GT.

\section{(2) Administração Aduaneira e Tributária}

O GT é denominado de Revenue Administration Steering Group (RASG). No encontro do grupo ocorrido em setembro de 2008, em Nova Déli, houve uma reunião dos Chefes das Administrações Aduaneiras e Tributárias dos três países. Emergiram do encontro posições comuns sobre arrecadação de grandes contribuintes e sobre auditoria e investigação, além de ter sido sugerida a formalização de um mecanismo de compartilhamento de informações, que reforçaria a cooperação já existente. Também é parte do trabalho do GT a busca por superação de barreiras ao comércio dos países e ao investimento, de modo que os Estados devem buscar a cooperação para o reconhecimento mútuo de operações econômicas e de estratégias de gestão das fronteiras e aduanas, de modo a facilitar os fluxos comerciais entre os envolvidos.

Em 2009, foram instituídas no organograma do MRE a Divisão de Acesso aos Mercados (DACESS), responsável pelas relações aduaneiras, e a Divisão de Cooperação Financeira e Tributária (DCF), que assume a responsabilidade pelas relações tributárias. Destaca-se a criação da Subsecretaria Geral de Assuntos Econômicos e Financeiros, responsável pela agenda externa de negociações e acordos nesse setor.

Todavia, o Ponto Nodal deste GT ainda se encontra na Receita Federal, que é o órgão responsável pelas principais ações de cooperação desenvolvidas por este GT. A criação destas novas divisões no MRE aponta a emergência destes temas na agenda internacional do país, devido à multiplicação dos fluxos não apenas comerciais e financeiros, mas também de serviços e de trabalhadores entres os países. 


\section{(3) Agricultura}

As reuniões do GT vêm sendo realizadas periodicamente. Em reunião ocorrida em maio de 2008, cada uma das partes se comprometeu a realizar dez seminários e/ou programas de treinamentos no sentido de ampliar e avançar na cooperação trilateral.

Foi realizado em Brasília, em agosto de 2008, um seminário sobre rastreabilidade e melhoramento genético animal, mas nesse evento a parte sul-africana não pôde enviar representante. Houve a tentativa de realização de um seminário sobre influenza aviária. Entretanto, isso não foi possível, em função de divergências de datas entre os Estados. Houve ainda, por parte dos indianos, a apresentação de documento intitulado "The future of agricultural cooperation in IBSA".

Avalia-se como sendo bom o ritmo de trabalho. Porém, as partes têm dificuldades de executar os projetos e de implementar os acordos, especialmente devido à diversidade de interesses quanto aos temas tratados no GT, especialmente sobre o agronegócio.

Cabe destacar que, em cooperação com o Ministério da Agricultura, Pecuária e Abastecimento (MAPA), a Divisão de Produtos de Base (DPB), do MRE, é uma das instituições vinculadas à execução das políticas propostas para o GT, havendo também participação da sociedade civil, por meio de instituições como a Confederação Nacional de Agricultura.

\section{(4) Assentamentos Humanos}

O Ponto Nodal desse GT está no Ministério das Cidades. O GT trata especialmente da melhoria das condições de vida da população de áreas urbanas mais pobres, como nas favelas. Também é parte das ações de implementação das políticas do GT a assinatura do Memorando de Entendimento sobre Desenvolvimento e Assentamentos Humanos. Busca-se também a realização de estudos comparativos de projetos bem-sucedidos nos três países, neste caso com a possibilidade de ampliação dos estudos para as áreas de obras públicas e águas, incluindo questões de saneamento. Ainda como parte da implementação das políticas do GT, a Índia ficou responsável pela organização de um seminário sobre "O desafio das favelas", no ano de 2010. 


\section{(5) Ciência e Tecnologia}

Com um rol bastante diferenciado de assuntos a serem trabalhados, o GT divide-se em vários subgrupos, e em alguns aspectos parece "invadir" a área temática de outros GTs, como o de Saúde, na questão das pesquisas sobre doenças, e o de Meio Ambiente, na pesquisa antártica. Esses dois assuntos são prioritários para as ações do GT, assim como o são a biotecnologia e a biossegurança, nanotecnologia e novas fontes de energia - neste último caso, numa interface com o GT de Energia. Percebe-se, assim, que há sobreposições temáticas que demandam melhor articulação entre os GTs, o que adensa e complexifica o trabalho de coordenação intragovernamental, para que seja evitada a duplicidade de trabalho ou a divergência de posicionamentos e estratégias.

A primeira reunião do Grupo foi realizada em 2004, em Nova Déli, quando foram identificadas as áreas prioritárias a serem desenvolvidas no Grupo de Trabalho. Em 2005, na II Reunião de Chanceleres do IBAS, assinou-se a "Declaração do Rio sobre Ciência e Tecnologia", quando foi definido o plano de trabalho de 2005-2007, que definia as principais linhas de cooperação para o GT, além de programar alguns seminários e eventos a serem executados durante esse intervalo. Em 2006 foi realizada, em Angra dos Reis, a III Reunião de Ministros de Ciência e Tecnologia do IBAS, ocasião em que ficou acordada a criação de um fundo de apoio a medidas concretas de cooperação trilateral, financiado pelos três países com um montante total de US\$ 3 milhões.

A questão da pesquisa antártica foi incorporada às atividades do GT em junho de 2008, durante a 31 a Reunião Consultiva do Tratado da Antártida (ATCM), e vem ganhando importância. Neste sentido, o Brasil e a África do Sul já disponibilizaram suas estações para intercâmbio de técnicos entre os países, tendo sido realizado o primeiro intercâmbio em março de 2009. Foi realizado também o "Simpósio IBAS Antártida", no Brasil, aproveitando a definição de 2009 como o Ano Polar Internacional.

Cabe destacar que existem alguns temas comuns entre o GT de Ciência e Tecnologia e o de Saúde, como a questão dos fármacos, ficando a pesquisa por conta do primeiro e o segundo por conta da distribuição dos medicamentos. E ainda com o GT de Meio Ambiente, na questão antártica, no referente ao tema da mudança climática. 
Apesar de toda essa sobreposição temática, o responsável pela coordenação do GT, ou seja, o Ponto Nodal do GT, encontra-se no MCT, em sua Secretaria de Relações Internacionais. Cumpre, todavia, registrar que o MRE tem hoje em seu organograma uma Subsecretaria Geral de Energia e Alta Tecnologia.

\section{(6) Comércio e Investimentos}

O GT de Comércio e Investimentos é constituído por três segmentos principais: um responsável pelos acordos comerciais entre os blocos econômicos (MERCOSUL - SACU ${ }^{8}$ - Índia), sob responsabilidade da DNC (Divisão de Negociações Extrarregionais do Mercosul I); outro que cuida do comércio em geral; e um terceiro, responsável pelos investimentos, ambos sob coordenação, no Brasil, da Divisão de Informação Comercial (DIC), do MRE. Também compõem o organograma brasileiro do GT, além dessas Divisões, o Ministério do Desenvolvimento, Indústria e Comércio Exterior (MDIC) e a própria DIB.

A facilitação do comércio passa pela diminuição de entraves burocráticos à exportação, um dos temas mais importantes das políticas de cooperação desenvolvidas no GT. Todavia, o comércio está relacionado também com a regulamentação das Normas e dos Regulamentos Técnicos. Nesse sentido, além do MDIC e do MRE, importa ressaltar a participação da Associação Brasileira de Normas Técnicas (ABNT) e do Instituto Nacional de Metrologia, Qualidade e Tecnologia (Inmetro) como órgãos parceiros neste GT.

No que diz respeito às negociações para a criação da área de livre comércio que poderá vir a unir MERCOSUL-Índia-SACU, as negociações estão bem avançadas. Caso concretizado, este acordo gerará a maior área de livre comércio entre países em desenvolvimento, com quase um bilhão e meio de pessoas e um PIB de mais de dois trilhões de dólares.

Um aspecto importante da atuação do GT de Comércio e Investimento é a cooperação entre pequenas empresas, iniciativa essa oriunda da articulação entre três órgãos, o SEBRAE, a Small Enterprise Development Agency (SEDA), da África do Sul, e a National Small Industry Corporation Ltd. (NSIC), da Índia, que agora é parte do GT. Para a incorporação desta temática, foi criado um subgrupo específico. 
Com a criação da Subsecretaria Geral de Cooperação, Cultura e Promoção Comercial, o Departamento de Promoção Comercial e Investimentos ficou como responsável pela coordenação das ações do GT no Brasil.

\section{(7) Cultura}

O Ponto Nodal do GT está sob responsabilidade da Divisão de Operações de Difusão Cultural, dentro do Departamento Cultural do MRE.

Já foram realizados Festivais de Dança (realizado no Brasil em outubro de 2007), de Cinema (realizado na Índia, nas cidades de Mumbai, Goa e Déli, em outubro de 2008) e de Gastronomia (realizado durante a III Cúpula de Presidentes, em outubro de 2008) para divulgação da cultura dos países. Cabe ainda destacar a participação do Brasil em feiras e eventos de promoção cultural nos outros dois países.

Para o futuro o GT espera realizar seminários sobre conservação do patrimônio cultural dos países-membros. Para tanto haverá participação do Instituto do Patrimônio Histórico e Artístico Nacional (IPHAN), como instituição que irá auxiliar o MRE neste projeto. Prepara-se, também, um seminário sobre conhecimentos tradicionais e cultura indígena (Indigenous Knowledge Systems).

\section{(8) Defesa}

Uma das questões mais sensíveis ao GT é a cooperação em temas nucleares. Nesse aspecto a cooperação bilateral entre Brasil e África do Sul está num nível mais avançado, posto que está em curso o desenvolvimento do projeto de criação de um míssil de curto alcance. No entanto, cabe registrar a preferência do Ministério da Defesa brasileiro pelos mecanismos trilaterais para o tratamento de certas áreas de cooperação, que vinham sendo previamente realizadas de modo bilateral com cada um dos Estados.

No âmbito organizacional doméstico, a gerência do GT de Defesa está sob a responsabilidade do Ministério da Defesa, em cooperação com a Secretaria Geral (SG) do MRE, bem como com a própria DIB. O Ponto Focal do GT, contudo, está localizado no Ministério da Defesa. A cooperação em questões nucleares também fica sob a responsabilidade do GT de Defesa, e não do GT de Energia, que tem trabalhado principalmente com fontes alternativas. 


\section{(9) Desenvolvimento Social}

São temas importantes para o GT: estratégias de alívio à pobreza, microfinanças, sistema de conhecimentos tradicionais, seguridade social, políticas sociais e desenvolvimento de capacidade institucional, todos visando o monitoramento e avaliação das atividades, bem como a cooperação em outros foros multilaterais. Cabe destacar que importa principalmente para o GT o intercâmbio de experiências entre as partes, uma vez que há problemas comuns aos países e que cada um mantém uma série de projetos bem-sucedidos, passíveis de serem compartilhados.

Fazem parte da estrutura do GT funcionários da Divisão de Temas Sociais do MRE, bem como do MDS, estando o Ponto Nodal localizado na Assessoria Internacional do Ministério do Desenvolvimento Social (MDS). O Fundo IBAS trabalha em parceria com o GT de Desenvolvimento Social, mesmo não havendo ações do Fundo nos países-membros do Fórum.

\section{(10) Educação}

O Ponto Nodal encontra-se no Ministério da Educação, apesar da forte participação do Ministério dos Esportes nesse GT.

Em julho de 2007 foi realizado um seminário acadêmico junto da reunião do GT. Durante a II Cúpula foram definidas as grandes áreas temáticas da cooperação científica entre as partes, a saber: transformação e coesão social; governança global e comércio e investimentos; engenharia, matemática e ciências da computação; biotecnologia, agricultura e pecuária; desenvolvimento sustentável; e educação superior.

Já no âmbito da cooperação de academias diplomáticas, houve dois encontros entre seus diretores, um no Brasil, em setembro de 2007, e outro em setembro de 2008, já tendo ocorrido intercâmbio entre diplomatas dessas academias. Existe em vigor um Memorando de Entendimento (ME) em Educação Superior. O ME sobre Cooperação de Academias Diplomáticas está sendo negociado entre os países.

No Memorando de Entendimento em Educação Superior estão delineados os objetivos a serem seguidos para a efetiva cooperação do GT. Em resumo, eles tratam da criação de condições para a cooperação entre instituições acadêmicas, faculdades, pesquisadores e estudantes, buscando fomentar o desenvolvimento de projetos conjuntos de pes- 
quisa. Procura-se, também, o alinhamento dos respectivos sistemas de educação superior, buscando o desenvolvimento social e econômico das comunidades locais, bem como o fortalecimento do treinamento e do desenvolvimento de programas com recursos humanos de alto nível.

\section{(11) Energia}

Durante a reunião do GT de 2007, destacou-se a proposta indiana de promoção do biodiesel, pois para as três partes o desenvolvimento de fontes de energia renováveis apresenta-se como política importante a ser fomentada. Além do biodiesel, fazem parte das ações de cooperação a busca de desenvolvimento dos recursos eólicos, que conta com um Memorando de Entendimento, em vigor desde outubro de 2007 tendo sido oferecida pelo lado indiano sua tecnologia de produção de energia eólica, biomassa e solar, tema de grande centralidade na Índia, que tem um Ministério específico dedicado às energias limpas e renováveis.

Quanto à questão dos biocombustíveis, a Índia comprometeu-se, durante a reunião do GT realizada em Nova Déli em setembro de 2008, a finalizar a tramitação referente à ratificação do Memorando de Entendimento. Também houve interesse das petrolíferas indianas na produção de etanol a partir de cana-de-açúcar, tendo sido criado, para tanto, um subgrupo de agroenergia.

Coube ainda à representação indiana apresentar suas preocupações sobre segurança alimentar e produção de biocombustíveis, tendo sido proposta a realização de um seminário. Foram propostos também projetos conjuntos nos termos de Comércio de Carbono e Mecanismo de Desenvolvimento Limpo, sendo, assim, os biocombustíveis o foco principal do GT. Por parte do MRE, o tema está sendo tratado pela Divisão de Recursos Energéticos Novos e Renováveis (DNR), do Departamento de Energia. O Ponto Nodal é, contudo, a Chefe da Assessoria Internacional do Ministério das Minas e Energia (MME).

\section{(12) Meio Ambiente e Mudança Climática}

Apenas em setembro de 2008 houve a primeira reunião oficial do GT, devido às diferentes posições das partes sobre o tema Meio Ambiente, ficando inicialmente acordado que o seu enfoque deveria recair sobre as mudanças climáticas. 
Para o futuro, busca-se inserir nos temas abordados pelo GT a cooperação em termos de espécies invasoras (ou seja, espécies não nativas), proteção dos países megadiversos, além do melhor aproveitamento do conhecimento tradicional, recursos biológicos e biossegurança.

Administra este GT, no Brasil, o Ministério do Meio Ambiente (MMA), em cooperação com a Divisão de Política Ambiental e Desenvolvimento Sustentável (DPAD) do MRE. Todavia, cabe ao MRE a responsabilidade central sobre o tema, uma vez que é parte das atribuições do MMA a execução de políticas domésticas de conservação ambiental, ficando a cargo do MRE a execução das relações exteriores sobre o tema. Em outubro de 2008 foi assinado, durante a III Cúpula, o Memorando de Entendimento sobre a questão.

\section{(13) Saúde}

Entre os principais assuntos trabalhados pelo GT estão: serviços laboratoriais, medicina tradicional, vigilância epidemiológica, desenvolvimento de ações nas áreas de HIV / AIDS, tuberculose e malária e contrafação (falsificação) de medicamentos. Nos temas concernentes a doenças como AIDS, tuberculose e malária, o programa do GT de Saúde confunde-se com o GT de Ciência e Tecnologia, que trabalha na pesquisa e desenvolvimento de novos medicamentos para essas doenças. Deste modo, fica por conta do GT de Saúde a prevenção, o controle e a distribuição de medicamentos, ao passo que o GT de Ciência e Tecnologia se encarrega do fomento ao desenvolvimento de novas tecnologias.

Estão envolvidos no GT de Saúde, em âmbito doméstico, por parte do MRE, o Departamento de Direitos Humanos e Temas Sociais (DHS), mais especificamente sob a tutela da Divisão de Temas Sociais (DTS); e o Ministério da Saúde (MS), a partir da sua Assessoria Internacional, contando ainda com as parcerias da Agência Nacional de Vigilância Sanitária (Anvisa) e da Fundação Oswaldo Cruz (Fiocruz). A coordenação do GT é realizada a partir do Ministério da Saúde (MS), em cooperação com os outros agentes envolvidos. Cabe destacar que o Ponto Nodal desse GT é o Chefe da Assessoria Internacional do MS, sendo importante considerar que, funcionalmente, sua lotação é no MRE, tornando assim mais fácil e próximo o relacionamento entre MRE e MS.

É parte do plano de ação do GT a realização de Oficinas sobre Sistema de Vigilância Sanitária e Epidemiológica. Neste sentido, a Anvisa torna-se responsável pela organização. Com o objetivo de ampliar a troca 
de informações sobre o sistema de saúde dos três países, seus projetos sociais e laboratórios públicos, é parte do plano de ação realizar visitas técnicas entre as partes. Pode-se, portanto, afirmar que as partes ainda se encontram numa etapa de reconhecimento das ações e dos projetos desenvolvidos por cada membro, e só após esse período espera-se o desenvolvimento de ações conjuntas.

Há, no âmbito da OMC, debates sobre a questão dos conhecimentos tradicionais e da propriedade intelectual, havendo uma convergência entre os interesses de Índia, Brasil e África do Sul, que foram previamente negociados entre as partes por meio das reuniões do IBAS. Importa, portanto, este compartilhamento de informações entre os países não apenas para cooperação técnica entre os mesmos, mas também para a concertação política entre eles, de modo a fortalecer suas posições e interesses no sistema internacional e em fóruns multilaterais. Busca-se tanto obter resultados mais favoráveis para o Fórum IBAS como um bloco único de interesses, como a consecução de objetivos mais particulares de cada um dos países. Assim, podemos apresentar o tema HIV / AIDS como exemplo de que, em alguns casos, há diferentes interesses entre os países, no caso complementares, na busca pela possibilidade de quebra de patentes farmacêuticas, a saber: para a Índia interessa a fabricação dos fármacos, para o Brasil a quebra de patentes e, para a África do Sul, a possibilidade de usar esses medicamentos no atendimento da sua imensa população infectada.

\section{(14) Sociedade da Informação}

O GT funciona principalmente baseado nos Planos de Ação, elaborados ao longo de diversos encontros. O novo Plano de Ação previa um programa de inclusão digital, o desenvolvimento de uma página eletrônica e uma série de Oficinas em Sociedade de Informação.

Houve também a designação ad hoc dos países que ficariam responsáveis pelo desenvolvimento das atividades, restando ao Brasil o ponto sobre inclusão digital, que deve ser desenvolvido a partir de projetos para a implantação de várias formas de inclusão digital, com a criação de centros de acesso, especialmente em áreas rurais mais remotas. $\mathrm{O}$ tema do governo eletrônico também ficou sob coordenação brasileira. Para esse tema importa buscar o desenvolvimento de uma metodologia para a administração da qualidade total das informações sobre dados governamentais. 
Sob a responsabilidade da África do Sul ficou a criação do site oficial, a criação de um Fórum IBAS de Tecnologias da Informação e da Comunicação (TIC), para que as municipalidades e os governos locais possam trocar informações, além da criação de uma metodologia para os padrões de indicadores de governo eletrônico. Já para a Índia ficou a responsabilidade pelo desenvolvimento de uma arquitetura de Integração e Operabilidade das Normas Governamentais sobre Sociedade da Informação.

Na Estrutura de Cooperação em Sociedade da Informação está definido que seriam responsáveis pelo GT, na Índia, o Ministério das Comunicações e Tecnologias da Informação; na África do Sul, o Ministério das Comunicações; e, no Brasil, todos os Ministérios e Agências Governamentais envolvidos diretamente com a Sociedade da Informação e as TICs, sob a coordenação do Ministério das Relações Exteriores. Todavia, hoje, em virtude de a um maior desenvolvimento do tema, o Ministério do Planejamento, Orçamento e Gestão (MPOG) assumiu a coordenação do GT, fazendo-o a partir do Departamento de Governo Eletrônico.

\section{(15) Transporte}

É parte essencial das ações deste grupo aumentar a quantidade de rotas marítimas e aéreas entre os países, de modo a fomentar as trocas comerciais, turísticas e culturais entre os três Estados. A necessidade de maior conectividade física entre os países-membros é um dos problemas apontados pelo Fórum Empresarial do IBAS.

Foi elaborado um plano de trabalho para o subgrupo de transporte marítimo que apresenta oito grandes projetos, a saber: cooperação entre empresas de navegação; capacitação de recursos humanos; intercâmbio sobre fluxo entre portos; regulação do setor; cooperação entre estaleiros; operação portuária e desenvolvimento de hubs.

Já os projetos previstos para o setor aéreo incluem: arranjos de code share; investigação de acidentes; segurança; certificação de produtos; intercâmbio de tecnologias; treinamentos e cooperação no transporte de cargas. Busca-se ampliar para o setor o número de rotas comerciais entre os três Estados.

Participam do GT, no subgrupo marítimo, a Agência Nacional Transportes Aquáticos (ANTAQ), a Secretaria Especial de Portos da Presi- 
dência (SEP), o Ministério do Desenvolvimento, Indústria e Comércio Exterior (MDIC) e a Marinha. No subgrupo de transporte aéreo encontramos a Agência Nacional de Aviação Civil (ANAC), a Empresa Brasileira de Infraestrutura Aeroportuária (Infraero), o Centro de Investigação e Prevenção de Acidentes Aeronáuticos (Cenipa) e o Departamento de Controle do Espaço Aéreo (Decea), além da Divisão de Negociações de Serviços (DNS) do MRE, que é a responsável por gerenciar as atividades do GT. Cabe destacar, ainda, que não há uma participação efetiva e direta do Ministério dos Transportes, pois há uma grande fragmentação das atividades deste Ministério em Agências Reguladoras, que são responsáveis pelas políticas do setor, sendo sua participação nas atividades do GT mais apropriada do que a do próprio Ministério dos Transportes.

\section{(16) Turismo}

Nesta área, mais uma vez, há sobreposição de conteúdos entre os GTs, neste caso com o GT de Transportes, para que o problema logístico de conexão aérea entre os países possa ser solucionado. Também em função desse impasse, o intercâmbio turístico dos países é pequeno, apesar de se verificar um grande potencial a ser explorado não apenas em termos de fluxos turísticos, mas em políticas de incentivo às atividades da área, com destaque para a exploração de parques naturais na África do Sul, cujo know how pode ser facilmente aplicado no Brasil. A Índia, em especial, está interessada em inverter seu fluxo turístico, que é maior no envio do que na recepção de turistas. No mesmo sentido, parece interessante para o Brasil aumentar o fluxo de turistas indianos, que em sua maioria preferem visitar a Europa e a América do Norte.

Como atividades mais práticas, foram realizados seminários para operadores de turismo e diversas atividades de divulgação cultural, como festivais de cinema e gastronomia, além da participação brasileira numa feira de artesanato na Índia (tendo o Brasil sido o único país da América a ser convidado para participar), entre outros eventos.

A Divisão de Feiras e Turismo (DFT) do MRE é a responsável pela coordenação das atividades do GT, trabalhando em parceria com o Ministério do Turismo. Existe ainda, embora em fase de desenvolvimento, um acordo trilateral para o GT de Turismo, sob os cuidados do Instituto Brasileiro de Turismo, ou Embratur, que foi assinado durante a III 
Cúpula do IBAS, realizada em outubro de 2008, cuja internalização ainda está sendo debatida pelo legislativo brasileiro.

Estão previstas como futuras atividades do GT a realização de Feiras de Turismo, a serem realizadas nos países para divulgar seus potenciais turísticos e aumentar o intercâmbio das partes. Outro tema emergente no GT de Turismo é o compartilhamento de informações e experiências entre África do Sul e Brasil, em virtude da realização das Copas do Mundo de Futebol de 2010 e 2014, respectivamente.

\section{BREVES CONSIDERAÇÕES FINAIS}

É interessante destacarmos que, na estrutura brasileira dos GTs, temos hoje dezesseis grupos em funcionamento, com igual número de Pontos Nodais existentes (na Índia são dezenove e na África do Sul são 21 os Pontos Nodais do IBAS). Essa flexibilidade organizacional resta evidente pela maneira singular como evoluiu cada área temática no âmbito da iniciativa IBAS (vide a descrição feita ao longo da seção anterior do artigo), demonstrando assim a autonomia desfrutada pelos GTs e/ou as dificuldades de criação ou subdivisão dos grupos; e denotando, ainda, que é sempre possível fazer avançar as prioridades políticas estabelecidas, a despeito (ou por causa) da estrutura de coordenação e de suas especificidades.

Como visto, é a partir da estrutura dos Grupos de Trabalho que podemos verificar como se dá a implementação das ações do IBAS. Fica patente a sua grande capilaridade intragovernamental, ou seja, a densa articulação doméstica entre os diversos órgãos governamentais que se faz necessária para que tal iniciativa da política externa brasileira possa, enfim, ganhar concretude. São os seguintes os ministérios diretamente envolvidos nos GTs: (i) Planejamento, Orçamento e Gestão, (ii) Fazenda, (iii) Agricultura, Pecuária e Abastecimento, (iv) Cidades, (v) Ciência e Tecnologia, (vi) Desenvolvimento, Indústria e Comércio, (vii) Cultura, (viii) Defesa, (ix) Desenvolvimento Social, (x) Esportes, (xi) Educação, (xii) Minas e Energia, (xiii) Meio Ambiente, (xiv) Saúde e (xv) Turismo. Há também, por certo, o envolvimento de diversos outros órgãos e secretarias do governo federal. Na estrutura organizacional da administração federal brasileira, todos os principais órgãos que compõem os GTs estão num mesmo nível hierárquico, ou seja, são ministérios ou órgãos do executivo federal que atuam de modo independente, submetidos apenas à Presidência da República - o que, com cer- 
ta frequência, levou a sobreposições e redundâncias em ações implementadas no âmbito da iniciativa IBAS. Ademais, se as clivagens organizacionais são temáticas, há que se considerar também, em função do presidencialismo de coalizão brasileiro, que esta estrutura é "loteada" entre os partidos que compõem a base política do presidente de turno, o que agrega outro elemento complicador para os esforços de coordenação intragovernamental.

Deve-se considerar, também, a existência de ministérios tradicionais, com burocracias e processos já consolidados, e outros de criação mais recente, o que sugere, por si só, modos de atuação mais ou menos cristalizados e, portanto, propensões diferentes ao insulamento e à cooperação. Em estruturas mais convencionais de Estado, ainda se parte do suposto de que toda política pública cujos efeitos estejam projetados para fora do território nacional deva ser implementada pelo respectivo ministério dos negócios estrangeiros, espécie de "guardião" (gatekeeper) da inserção internacional do país (Moses e Knutsen, 2001). O caso do IBAS ultrapassa, naturalmente, essa concepção tradicional. Há, assim, no âmbito dos GTs, dificuldades de coordenação e acompanhamento das atividades dos grupos, pesando também sobre o desenvolvimento das atividades os interesses de cada órgão específico frente às necessidades relativas às ações de política externa.

Alexander (1993) afirma que sistemas interorganizacionais e intraorganizacionais devem buscar a coordenação de suas atividades quando seu escopo e complexidade crescerem a ponto de não mais estarem contidos nos limites do simples controle hierárquico. No caso da coordenação doméstica das ações de política externa, uma multiplicação de temas da agenda internacional exigiu nos últimos anos, dos organismos formuladores e condutores, a busca por intercâmbios e parcerias em áreas e setores técnicos mais específicos, justificando-se, desse modo, a multiplicidade de atores envolvidos nas atividades domésticas do Fórum IBAS.

Diferentemente do que postulam alguns teóricos clássicos da disciplina acadêmica das relações internacionais, que tratam os governos como um bloco único de decisão e interesses, uma "caixa preta" lacrada e unitária, a estrutura do governo para implementação da política externa é constituída por um corpo burocrático extremamente complexo, por funcionários que têm posições, percepções e interesses muitas vezes distintos e incompatíveis entre si. 
Todavia, apesar da diversidade de objetivos entre os órgãos burocráticos envolvidos no IBAS, deve-se buscar a prevalência dos objetivos gerais delimitados pelos acordos assinados no Fórum. Todos os membros do IBAS buscam a cooperação para o desenvolvimento, sendo importante para a materialização da iniciativa não apenas a formulação, mas, sobretudo, a implementação das políticas nos três países.

A pluralidade de agências em interação para a implementação da política externa, considerando suas percepções, expectativas, recursos institucionais e rotinas organizacionais, pode gerar conflito de interesses e divergências no posicionamento dos atores governamentais. Alexander (1993) reforça que as estruturas de coordenação, como os coordenadores formais, são necessárias quando há horizontalidade entre as organizações envolvidas, situação que ocorre no âmbito intragovernamental.

Dos dezesseis GTs do IBAS, cinco estão sob a coordenação direta do MRE, isto é, os Pontos Nodais são funcionários do Itamaraty (GTs de Comércio, Cultura, Meio Ambiente, Transporte e Turismo). Talvez se possa pensar que essas cinco áreas são, precisamente, aquelas de interesse prioritário do MRE. Vale notarmos, ainda, que dos onze GTs que não estão sob a coordenação direta do Itamaraty, em apenas dois (Assentamentos Humanos e Sociedade da Informação) o Ponto Nodal não é parte da assessoria internacional, ou equivalente, do Ministério ou outro órgão federal responsável pelo GT (dados referentes a 2011). Este dado é significativo porque indica que os trabalhos estão sendo coordenados por pessoas que, mesmo não fazendo parte do corpo de funcionários do MRE, provavelmente têm interações frequentes com o Itamaraty, em razão de suas próprias atividades em seus órgãos de origem. Ademais, vale recordarmos que a Fundação Alexandre de Gusmão (Funag), vinculada ao MRE, ministra Cursos de Capacitação em Relações Internacionais especificamente para altos funcionários do governo federal, das autarquias e das agências reguladoras, os quais têm, por certo, objetivo de capacitação, de produção de visões e interesses convergentes e também de expansão e consolidação de uma rede intragovernamental de especialistas que tenha o Itamaraty como instituição de referência.

Cabe aqui uma breve menção às assessorias internacionais dos diversos órgãos do governo federal brasileiro. Como destacado por Faria (2009), dos 23 ministérios do governo Lula (dados de junho de 2009), 
todos, à exceção do MRE, por motivos óbvios, e do Ministério da Integração Nacional, tinham instituídas Secretarias de Relações Internacionais, Diretorias ou Assessorias de Assuntos Internacionais, ou órgãos semelhantes. Ademais, todas as oito secretarias que tinham status de ministério também possuíam instâncias com as mesmas funções, bem como os seis outros órgãos do governo federal que desfrutavam do mesmo status.

Esta "horizontalização da política externa brasileira", nos termos de França e Sanchez (2009), deve ser vista, obviamente, como evidência clara da perda de monopólio do Itamaraty sobre a agenda internacional brasileira, derivada do indefectível processo de globalização, da consequente fragilização generalizada das fronteiras entre o doméstico e o internacional e do adensamento das relações internacionais do país. Contudo, como evidenciado pela experiência da implementação das diretrizes do IBAS no país, o MRE parece estar atuando intensamente no sentido da ampliação de sua capacidade de coordenação interministerial. Dito de outra maneira, o que pode ser visto, por um lado, como concorrência intragovernamental na definição da agenda internacional do país parece estar redundando, por outro lado, em mais atenção do MRE não apenas aos atores societários, mas também ao nível intragovernamental, para além de suas tradicionais atribuições no plano internacional.

Em síntese, o caso que estudamos neste artigo traz indícios consistentes de que a histórica relação tutelar que o Itamaraty mantém com a política externa brasileira permaneceu por meio de outras fórmulas, em que pesem a aparição de novos stakeholders nas relações internacionais do país e o crescente compartilhamento de papéis institucionais (no relativo à condução da PEB) no seio do aparelho de Estado. O exemplo do Fórum IBAS bem ilustra como a fase da implementação passou a constituir, para o MRE, um dos nervos mais sensíveis do processo de fabricação da política exterior, dada a complexidade técnica dos assuntos envolvidos e a diversidade dos interesses que se cruzam no interior das burocracias governamentais. A necessidade de uma coordenação intragovernamental eficiente entre essas agências tem levado o Ministério das Relações Exteriores a reposicionar-se no ciclo de policymaking da PEB - passando da condição de operador preferencial e praticamente onipresente, pela via diplomática, para uma função mais propria- 
Coordenação Intragovernamental para a Implementação da Política...

mente supervisora e articuladora das dinâmicas de cooperação internacional do Brasil.

(Recebido para publicação em abril de 2011)

(Versão reapresentada em outubro de 2011)

(Aprovado para publicação em fevereiro de 2012) 


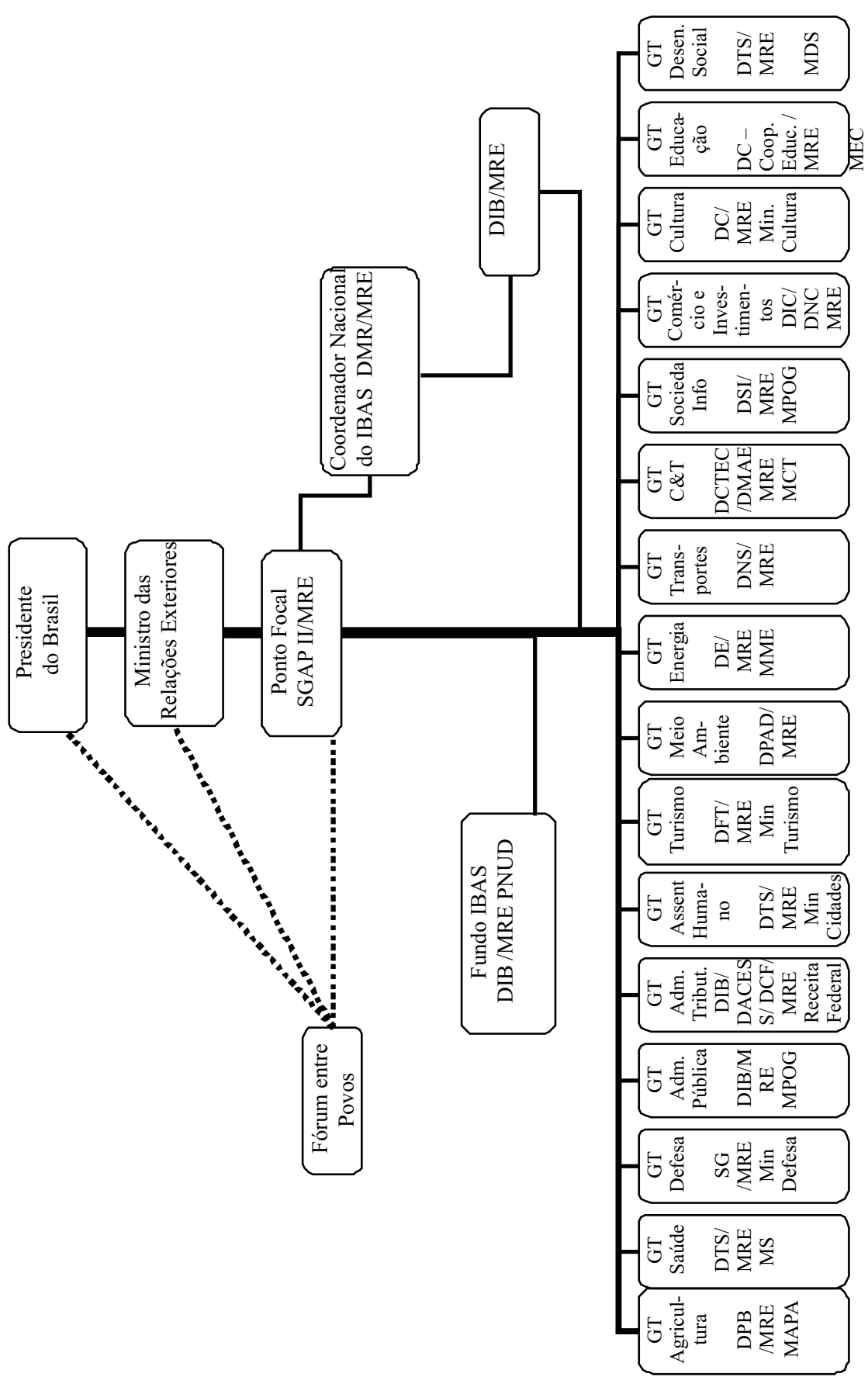




\section{NOTAS}

1. Fonte: Newsletter da FUNAG de 18/6/2009, capturado em 8/7/2009, disponível em http:/ / www.funag.gov.br/newsletter/newslettertheme/newsletter.2009-06$18.7639762201 /$ view

2. Sítio eletrônico do Fórum IBAS. Disponível em: http:/ / www.ibsa-trilateral.org/

3. O Fundo IBAS é um Fundo de Combate à Fome è̀ Pobreza, criado e financiado pelos três países do IBAS, que objetivam desenvolver projetos autossustentáveis para beneficiar países em desenvolvimento. Este é mais um dos ineditismos do IBAS, pois altera o círculo tradicional de doadores. Os recursos do Fundo são administrados pela Unidade Especial de Cooperação Sul-Sul (UECSS) do PNUD.

4. Disponível em: http://www.itamaraty.gov.br/temas-mais-informacoes/saibamais-ibas.

5. Disponíveis para consulta em: http://www.itamaraty.gov.br/temas-mais-informacoes/saiba-mais-ibas/documentos-emitidos-pelos-chefes-de-estado-e-de/view.

6. A discussão destes três pontos iniciais da seção sintetiza, em ampla medida, a argumentação de Faria, Rocha e Filgueiras (2006).

7. São as seguintes das fontes utilizadas nesta seção: entrevistas concedidas a Joana Laura Nogueira por diplomatas do DMR e Pontos Nodais do IBAS entre 2008 e 2009, além da pesquisa realizada nos arquivos setoriais da DIB/MRE. Ver, para mais detalhes, Nogueira (2009).

8. Southern African Customs Union, organização estabelecida em 1970 e integrada, hoje, por África do Sul, Botsuana, Lesotho, Suazilândia e Namíbia. 


\section{REFERÊNCIAS BIBLIOGRÁFICAS}

ALEXANDER, Ernest R. (1993), “Interorganizational Coordination: Theory and Practice". Journal of Planning Literature, vol. 7, no 4, pp. 328-343.

ALEXANDRE, Cristina Vieira M. (2006), O Congresso Brasileiro e a Política Externa (1985-2005). Dissertação de Mestrado, Programa de Pós-Graduação em Relações Internacionais, Rio de Janeiro, PUC-Rio.

. (2007), O Papel do Poder Legislativo na Política Externa Brasileira: O Caso dos Acordos Referentes ao Centro de Lançamentos de Alcântara. Trabalho apresentado no 1ํ Encontro da Associação Brasileira de Relações Internacionais (ABRI). Brasília, 25 a 27 de julho.

BARROS, Alexandre de S. C. (1986), “A Formulação e Implementação da Política Externa Brasileira: O Itamaraty e os Novos Atores", in H. Muñoz e J. Tulchin (eds.), A América Latina e a Política Mundial. São Paulo, Convívio, pp. 29-42.

BRASIL, Decreto no 5.979, de 6 de dezembro de 2006. Aprova a Estrutura Regimental e o Quadro Demonstrativo dos Cargos em Comissão e das Funções Gratificadas do Ministério das Relações Exteriores, e dá outras providências. Diário Oficial, Brasília, 7 de dezembro de 2006.

BELÉM LOPES, Dawisson. (2011), "A Política Externa Brasileira e a 'Circunstância Democrática': Do Silêncio Respeitoso à Politização Ruidosa". Revista Brasileira de Política Internacional, vol. 54, no 1, pp. 67-86.

e VELLOZO JÚNIOR, Joelson. (2004), “Balanço sobre a Inserção Internacional do Brasil". Contexto Internacional, vol. 26, no 2, pp. 317-353.

CARVALHO, Maria Izabel V. (2003), “Estruturas Domésticas e Grupos de Interesse: A Formação da Posição Brasileira para Seattle". Contexto Internacional, vol. 25, no 2, pp. 363-401.

CASON, Jeffrey e POWER, Timothy. (2006), Presidentialization, Pluralization, and the Rollback of Itamaraty: Explaining Change in Brazilian Foreign Policy Making from Cardoso to Lula. Trabalho apresentado na Conferência Regional Powers in Asia, Africa, Latin America, The Near and Middle East. Hamburgo, German Institute of Global and Area Studies, 11 e 12 de dezembro.

CERVO, Amado Luiz. (2010), "Brazil's Rise on the International Scene: Brazil and the World". Revista Brasileira de Política Internacional, vol. 53, número especial, pp.7-32.

e BUENO, Clodoaldo. (1992), História da Política Exterior do Brasil. São Paulo, Editora Ática.

CHEIBUB, Zairo B. (1985), “Diplomacia e Construção Institucional: O Itamaraty em uma Perspectiva Histórica". DADOS, vol. 28, no 1, pp. 113-131.

(1989), "A Carreira Diplomática no Brasil: O Processo de Burocratização do Itamarati". Revista de Administração Pública, vol. 23, no 2, pp. 97-128.

DINIZ, Simone e RIBEIRO, Cláudio. (2008), “The Role of the Brazilian Congress in Foreign Policy". Brazilian Political Science Review, vol. 2, no 2, pp. 10-38. 
(2010), “Acordos Internacionais e Controle Parlamentar no Brasil”. Revista de Sociologia e Política, vol. 18, no 37, pp.75-92.

FARIA, Carlos Aurélio Pimenta de. (2008), “Opinião Pública e Política Externa: Insulamento, Politização e Reforma na Produção da Política Exterior do Brasil". Revista Brasileira de Política Internacional, vol. 51, no 2, pp. 80-97.

. (2009), O Itamaraty e a Política Externa Brasileira: Do Insulamento à Busca de Coordenação dos Atores Governamentais e de Cooperação com os Agentes Societários. Trabalho apresentado no II Encontro da Associação Brasileira de Relações Internacionais/ISA. Rio de Janeiro, PUC-Rio, 22 a 24 de julho.

(2011), Implementação: Ainda o 'Elo Perdido' da Análise de Políticas Públicas no Brasil?. Trabalho apresentado no GT Políticas Públicas do 35o Encontro da Associação Nacional de Pós-Graduação em Ciências Sociais (Anpocs). Caxambu, MG, 24 a 28 de outubro.

, ROCHA, Carlos A. V. e FILGUEIRAS, Cristina A. C. (2006), “Cooperação Interorganizacional e Resiliência das Instituições: Notas sobre a Intersetorialidade na Gestão das Políticas Públicas". Pensar BH: Política Social, no 15, pp. 5-7.

FERREIRA, Marcelo Costa. (2010), “Os Processos Constituintes de 1946 e 1988 e a Definição do Papel do Congresso Nacional na Política Externa Brasileira”. Revista Brasileira de Política Internacional, vol. 53, no 2, pp. 23-48.

FIGUEIRA, Ariane Roder. (2010), “Rupturas e Continuidades no Padrão Organizacional e Decisório do Ministério das Relações Exteriores". Revista Brasileira de Política Internacional, vol. 53, no 2, pp. 5-22.

FRANÇA, Cássio e SANCHEZ, Michelle Ratton. (2009), “A Horizontalização da Política Externa Brasileira". Valor Econômico, 24/4/2009. Disponível em: http://www.google.com/notebook/public/03904464067865211657/BDQtiSwoQ4J3vvY0k. Acessado em 22 de junho de 2009.

JENNINGS JR., Edward T. e KRANE, Dale. (1994), “Coordination and Welfare: The Question for the Philosopher's Stone". Public Administration Review, vol. 54, no 4, pp. 341-348.

LIMA, Maria Regina Soares de. (2000), “Instituições Democráticas e Política Exterior". Contexto Internacional, vol. 22, no 2, pp. 265-304.

(2002), “O Legislativo e a Política Externa”, in A. Rebelo; L. Fernandes e C. H. Cardim (orgs.), Seminário Política Externa do Brasil para o Século XXI. Brasília, Câmara dos Deputados, pp. 41-51.

(2005), "A Política Externa Brasileira e os Desafios da Cooperação Sul-Sul”. Revista Brasileira de Política Internacional, vol. 48, no 1, pp. 24-59.

e SANTOS, Fabiano. (2001), “O Congresso e a Política de Comércio Exterior”. Lua Nova, no 52, pp. 121-150.

MAIA, Clarita C. e CESAR, Suzan E. M. (2004), “A Diplomacia Congressual. Análise Comparativa do Papel dos Legislativos Brasileiro e Norte-Americano na Formulação da Política Externa". Revista de Informação Legislativa, Ano 41, no 163, pp. 363-388. 
MOSES, Jonathon e KNUTSEN, Tobjorn. (2001), “Inside Out: Globalization and the Reorganization of Foreign Affairs Ministries". Cooperation and Conflict, vol. 36, no 4, pp. 355-380.

MOURA, Cristina Patriota de. (2006), “O Inglês, o Parentesco e o Elitismo na Casa de Rio Branco". Cena Internacional, Ano 8, no 1, pp. 20-34.

(2007), O Instituto Rio Branco e a Diplomacia Brasileira: Um Estudo de Carreira e Socialização. Rio de Janeiro, Editora FGV.

NEVES, João Augusto de Castro. (2003), “O Papel do Legislativo nas Negociações do Mercosul e da Alca". Cena Internacional, Ano 5, no 3, pp. 35-57.

. (2006). "O Congresso Nacional e a Política Externa Brasileira", in H. Altemani e A. C. Lessa (orgs.), Relações Internacionais do Brasil: Temas e Agendas. São Paulo, Ed. Saraiva, pp. 365-388.

NOGUEIRA, Joana L. M. (2009), A Articulação Doméstica da Burocracia Brasileira para a Implementação das Ações do Fórum IBAS. Dissertação de Mestrado, Programa de Pós-Graduação em Relações Internacionais, Belo Horizonte, PUC-Minas.

OLIVEIRA, Amâncio J. de. (2003), “Legislativo e Política Externa: Das (In)conveniências da Abdicação". Working Papers CAENI, no 3.

e PFEIFER, Alberto. (2006), “O Empresariado e a Política Exterior do Brasil”, in H. Altemani e A. C. Lessa (orgs.), Relações Internacionais do Brasil: Temas e Agendas. São Paulo, Ed. Saraiva, pp. 389-428.

OLIVEIRA, Amâncio J. de e ONUKI, Janina. (2007), “Grupos de Interesse e a Política Comercial Brasileira: A Atuação na Arena Legislativa". Papéis Legislativos, no 8, IUPERJ/OPSA/NECON.

OLIVEIRA, Marcelo Fernandes de. (2003), Mercosul: Atores Políticos e Grupos de Interesse Brasileiros. São Paulo, Editora UNESP.

PETERS, B. Guy. (1998), “Managing Horizontal Government: The Politics of Co-ordination". Public Administration, vol. 76, pp. 295-311.

PUNTIGLIANO, Andrés Rivarola. (2008), “Going Global: An Organizational Study of Brazilian Foreign Policy”. Revista Brasileira de Política Internacional, vol. 51, no 1, pp. 28-52.

REGENS, James L. (1988), “Institutional Coordination of Program Action: A Conceptual Analysis". International Journal of Public Administration, vol. 11, no 2, pp.135-154.

RICUPERO, Rubens. (2002), "Diversidade e Desenvolvimento", in G. Arbix, G. et alii (orgs.), Brasil, México, Índia, África do Sul e China: Diálogos entre os que Chegaram Depois. São Paulo, Edusp/Edunesp, pp. 25-42.

. (2004), "Oportunidade que Não se Repetirá Tão Cedo". Folha de S. Paulo, $9 / 5 / 2004$.

SACHS, Ignacy. (1997), "Brasil e Índia: Duas Baleias no Oceano Global”, in S. P. Guimarães (org.), Estratégias: Índia e Brasil. Brasília, IPRI, pp. 69-78.

SANTANA, Helton R. Presto. (2001), “Grupos de Interesse e a Política Externa Brasileira para a ALCA". Contexto Internacional, vol. 23, no 1, pp. 167-196. 
Coordenação Intragovernamental para a Implementação da Política...

SILVA, Elaini C. G.; SPÉCIE, Priscila e VITALE, Denise. (2010), “Atual Arranjo Institucional da Política Externa Brasileira". Texto para Discussão no 1.489, IPEA.

VIGEVANI, Tullo e MARIANO, Karina L. P. (1997), “A Burocracia na Integração Regional (e no Mercosul): Influência no Processo Decisório". Contexto Internacional, vol. 19, no 2, pp. 267-305.

WORLD BANK INDICATORS. (2002), Disponível em: www.worldbank.org. Acessado em 1 de março de 2004. 


\begin{abstract}
Intra-Governmental Coordination for Implementation of Brazil's Foreign Policy: the case of the IBSA Forum

This study evaluates the organizational mechanisms and structures adopted by the Brazilian Ministry of Foreign Affairs (Itamaraty) to promote the coordination of domestic government actors for implementing the guidelines of the IBSA Forum (India, Brazil, and South Africa), created in 2003. After reviewing some of the factors that have led Itamaraty to lose its traditional insulation, the authors classify the mechanisms for intra-governmental coordination and analyze its dynamics, focusing special attention on the 16 thematic working groups created to ensure the achievement of IBSA's objectives. In the final remarks, the authors question Itamaraty's purported loss of capacity for intra-governmental coordination.
\end{abstract}

Key words: Intra-governmental coordination; Itamaraty; Brazilian Foreign Policy; IBSA Forum

\title{
RÉSUMÉ \\ Coordination Intragouvernementale pour la Mise en Place de la Politique Extérieure Brésilienne: Le cas du Forum IBAS
}

Ce travail évalue les mécanismes et les structures organisationnelles adoptés par l'Itamaraty afin de promouvoir la coordination des acteurs gouvernementaux, au niveau interne, en vue de la mise en place des consignes du Forum IBAS (Inde, Brésil, Afrique du Sud) créé en 2003. A près avoir revu les facteurs qui ont amené l'Itamaraty à abandonner son traditionnel isolement, on classe les mécanismes de coordination intragouvernementale et on analyse leur dynamisme, avec une attention particulière concernant les 16 Groupes de Travail suivant des thèmes adoptés pour assurer la concrétisation des objectifs de l'IBAS. Dans les considérations finales, on cherche à savoir si en effet la compétence de coordination intragouvernementale de l'Itamaraty a subi une perte quelconque.

Mots-clés: coordination intragouvernementale; Itamaraty; politique extérieure brésilienne; Forum IBAS 